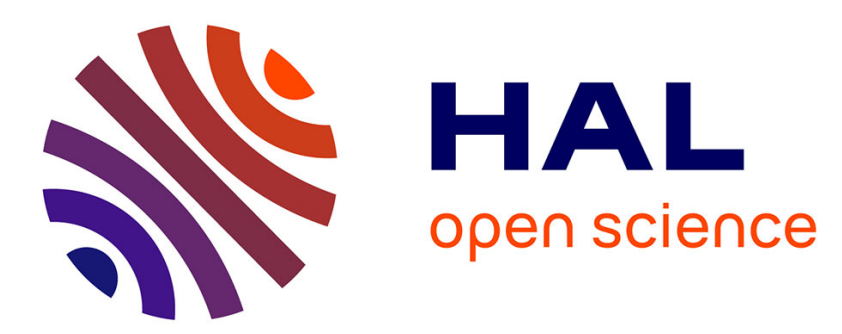

\title{
Numerical simulation of heat and mass transfer in bidispersed capillary structures: Application to the evaporator of a loop heat pipe
}

\author{
Laetitia Mottet, Marc Prat
}

\section{- To cite this version:}

Laetitia Mottet, Marc Prat. Numerical simulation of heat and mass transfer in bidispersed capillary structures: Application to the evaporator of a loop heat pipe. Applied Thermal Engineering, 2016, vol. 102, pp. 770-784. 10.1016/j.applthermaleng.2016.03.143 . hal-01432830

\author{
HAL Id: hal-01432830 \\ https://hal.science/hal-01432830
}

Submitted on 12 Jan 2017

HAL is a multi-disciplinary open access archive for the deposit and dissemination of scientific research documents, whether they are published or not. The documents may come from teaching and research institutions in France or abroad, or from public or private research centers.
L'archive ouverte pluridisciplinaire HAL, est destinée au dépôt et à la diffusion de documents scientifiques de niveau recherche, publiés ou non, émanant des établissements d'enseignement et de recherche français ou étrangers, des laboratoires publics ou privés. 


\section{OATAO}

\section{Open Archive TOULOUSE Archive Ouverte (OATAO)}

OATAO is an open access repository that collects the work of Toulouse researchers and makes it freely available over the web where possible.

This is an author-deposited version published in : http://oatao.univ-toulouse.fr/ Eprints ID : 17330

To link to this article : DOI:10.1016/j.applthermaleng.2016.03.143 URL : http://dx.doi.org/10.1016/j.applthermaleng.2016.03.143

To cite this version : Mottet, Laetitia and Prat, Marc Numerical simulation of heat and mass transfer in bidispersed capillary structures: Application to the evaporator of a loop heat pipe. (2016) Applied Thermal Engineering, vol. 102. pp. 770-784. ISSN 1359-4311

Any correspondence concerning this service should be sent to the repository administrator: staff-oatao@listes-diff.inp-toulouse.fr 


\title{
Numerical simulation of heat and mass transfer in bidispersed capillary structures: Application to the evaporator of a loop heat pipe
}

\author{
L. Mottet ${ }^{\mathrm{a}, \mathrm{c}, \mathrm{d}}$, M. Prat ${ }^{\mathrm{a}, \mathrm{b}, *}$ \\ ${ }^{a}$ Université de Toulouse, INPT, UPS, IMFT, Toulouse, France \\ ${ }^{\mathrm{b}} \mathrm{CNRS}$, IMFT, Toulouse, France \\ ${ }^{\mathrm{c}}$ Airbus Defence and Space, Toulouse, France \\ ${ }^{\mathrm{d}}$ Centre National d'Études Spatiales, Toulouse, France
}

Keywords:

Loop heat pipe

Capillary evaporators

Pore network model

Bidispersed wick

\begin{abstract}
A B S T R A C T
Heat and mass transfer with phase change in an evaporator unit cell is analysed using a mixed pore network model. Two different kind of wick are investigated: a monoporous capillary structure characterised by a monomodal pore size distribution and a bidispersed capillary structure characterised by a bimodal pore size distribution. The evaporator thermal performance, i.e. the conductance, and the overheating of the casing are compared at different heat loads with experimental results and show a good agreement. For a large range of flux, the bidispersed wick has higher thermal performance than the monoporous wick. A bidispersed wick prevents the overheating of the casing which is the most encountered limit in LHP application. The liquid-vapour phase distribution, as well as the vapour saturation and the vapour mass flow rate are investigated to explain these behaviours.
\end{abstract}

\section{Introduction}

Capillary pumped loops (CPL) and Loop heat pipes (LHPs) ([1]) are cooling devices used in space, aeronautic or terrestrial applications to meet the thermal control problems of advanced electronics. An LHP (see Fig. 1a) is composed of a condenser, a liquid and a vapour line, a compensation chamber and an evaporator. An LHP can be studied at the scale of the whole system, e.g. [2-4], or at the scale of only one of the components which is generally the evaporator since this is the place of the vaporisation process, e.g. $[5,6]$. The evaporator consists of a metallic casing, a porous wick, vapour grooves and a liquid-core. The heat flux that needs to be evacuated is transferred by conduction up to the porous wick through the metallic wall of the evaporator. This induces the vaporisation of the fluid and the formation of menisci at the surface and/or within the porous wick. The menisci adjust themselves to balance the total pressure drop in the others components of the loop. The vapour is then evacuated thanks to vapour grooves. A cross section of a cylindrical evaporator is depicted in Fig. 1b, where dashed lines delimit the evaporator unit cell shown in three-dimension in Fig. 1c.

\footnotetext{
* Corresponding author at: Université de Toulouse, INPT, UPS, IMFT, Toulouse, France.

E-mail address: mprat@imft.fr (M. Prat).
}

Heat and mass transfer in capillary evaporator have been studied when the vaporisation only occurs at the wick/groove interface (liquid saturated wick) ([8-10]) or within the wick (using the so-called "vapour pocket" assumption, e.g. [11-13]). However, a recent work [7] highlighted that a two-phase zone actually exists under the casing, as already supposed in [14-17], calling into question the relevance of the "vapour pocket" assumption in a three-dimensional capillary evaporator unit cell. As pointed out in [13], the most interesting regime, corresponding to the best evaporator performances, is actually the regime in which there is no vapour pocket and where liquid and vapour coexist within the wick. Identifying the correct operation regime is of course crucial in the prospect of designing better evaporators. Several parameters and/or properties have been investigated numerically and/or experimentally in order to improve the evaporator performances. Amongst other the geometrical dimensions and the position of vapour grooves [10], the choice of the working fluid $([18,19])$ or the use of a bilayer wick ([20-22]) were investigated. In this context, the use of a bimodal capillary wick has been considered in the literature and seems to be promising to improve LHP performance.

Bimodal structures are characterised by the existence of two distinct pore size distributions It exists essentially two methods to manufacture them inducing a structural difference ([23]). The first method collects together small pore particles into clusters, leading to a so-called "bidispersed" structure. Large pores are 


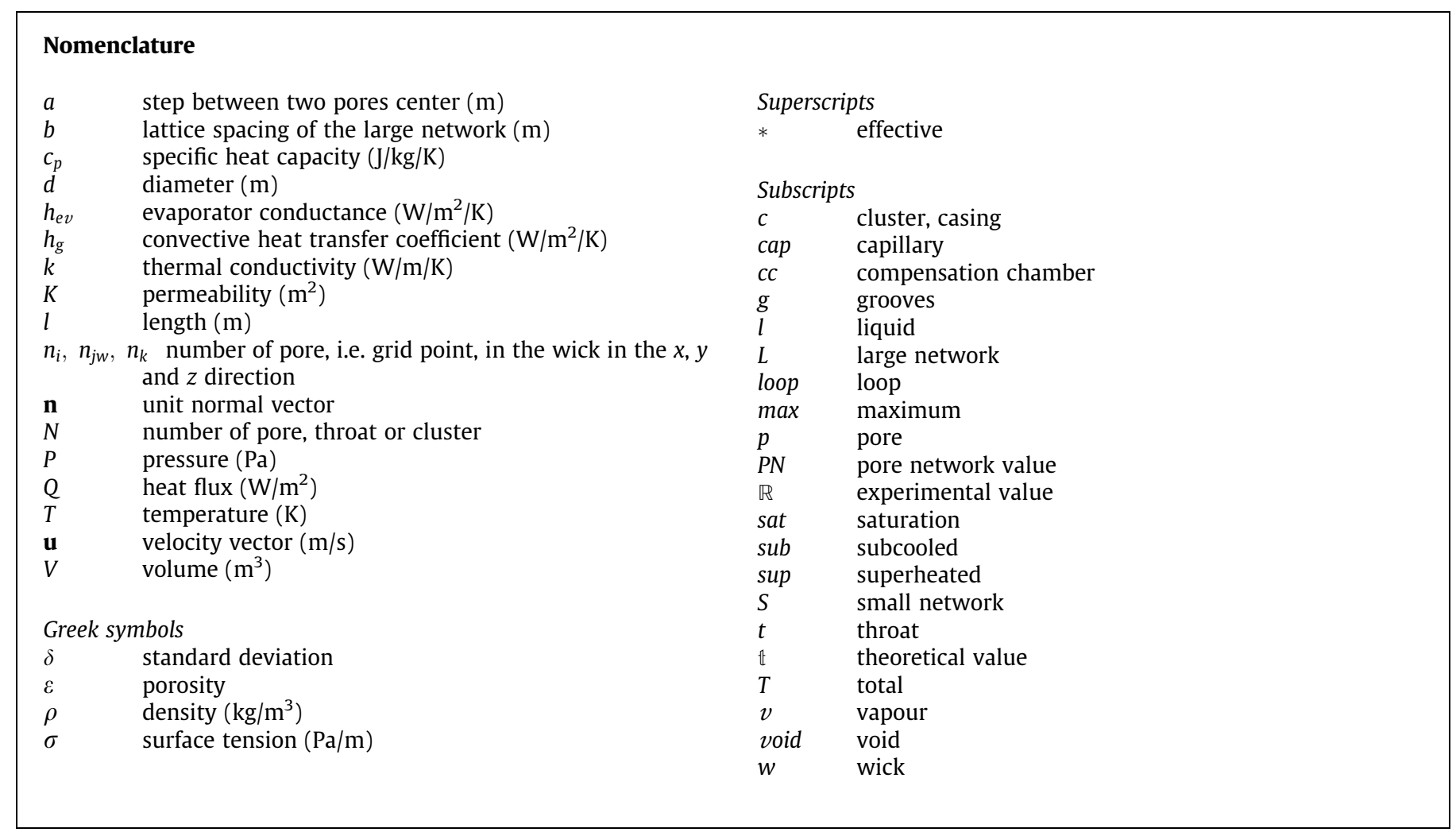

located between clusters of small pores (Fig. 2a). The second method consists in sintering a mix of powder and pore formers. The pore formers are then removed through a dissolution or evaporation process. In that case, large pores are located at the places of the pore formers (Fig. 2b), creating a so-called "biporous" structure. Scanning electron microscopy (SEM) images of a bidispersed structure and a biporous one are shown in Fig. 3. The large pores create preferential paths for the vapour while the small pores

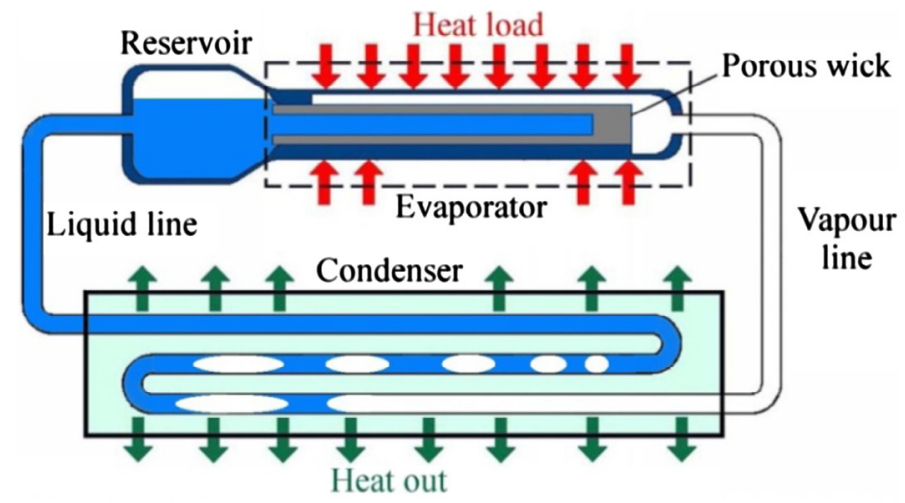

(a)

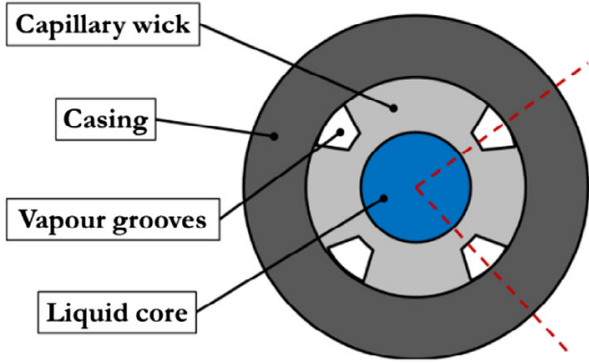

(b)

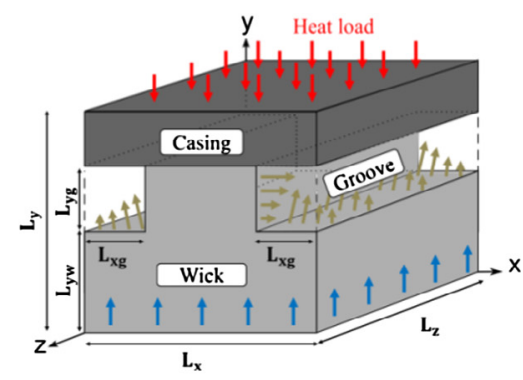

(c)

Fig. 1. (a) Schematic of a LHP; (b) cross section of a cylindrical evaporator and (c) evaporator unit cell delimited by the red dashed line in (b). Reprinted from [7] with permission from Elsevier. (For interpretation of the references to colour in this figure legend, the reader is referred to the web version of this article.) 


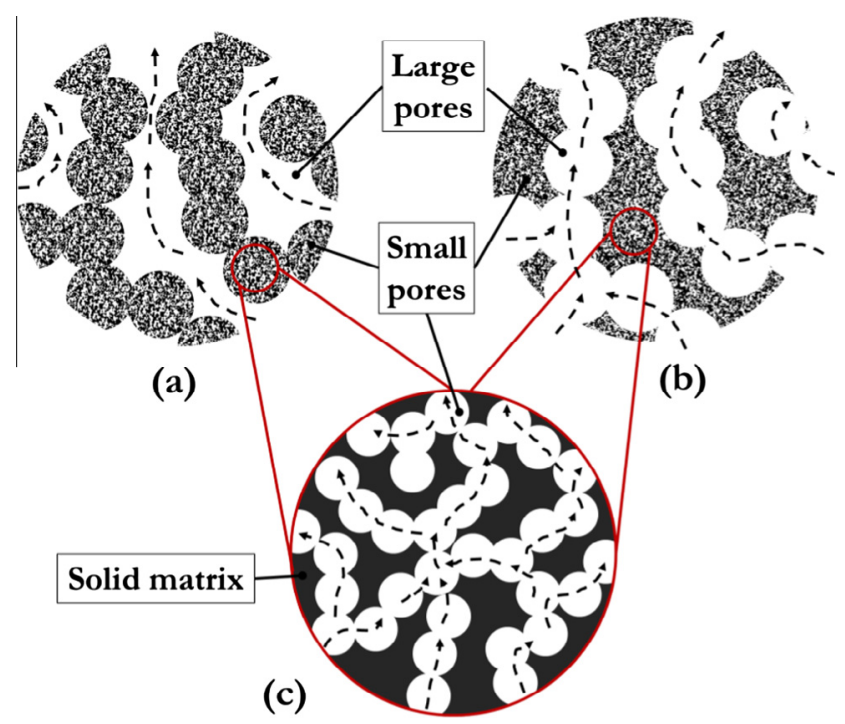

Fig. 2. Schematic structure of a bimodal porous medium for (a) a bidispersed wick and (b) a biporous wick. The arrow indicates the flow paths. Adapted from Rasor and Desplat [23].

permit to increase the evaporation surface area and the number of menisci, which improve the transport of the liquid ([25]). It is therefore expected that the bimodal structure improves the performances through more appropriate liquid and vapour phase distributions within the wick when vaporisation occurs inside the capillary structure.

Several experimental studies were devoted to bidispersed wicks applied to LHP evaporators and several important parameters impacting the performance have been analysed. The optimal ratio between small pores and large pores was investigated in [26]. The influence of wick thickness, small pore size and cluster size on dryout values, on the evaporator wall overheating and on the heat transfer coefficient was studied in several papers published by the group of Catton ([27-31]). The $63 \mu \mathrm{m}-455 \mu \mathrm{m}-3 \mathrm{~mm}$ (small pore diameter-cluster diameter-thickness of the wick) wick structure [31] was the most appropriate to evacuate high heat flux (around $990 \mathrm{~W} / \mathrm{cm}^{2}$ ). However, their analysis of the heat transfer coefficient showed that the $40 \mu \mathrm{m}-300 \mu \mathrm{m}-1 \mathrm{~mm}$ structure [30] led to the highest value. Indeed, the evaporative performance is duly enhanced by decreasing the size of clusters, as it was also shown in [32].

More recently, studies have turned to the use of biporous wick structures for LHP as their manufacturing method permits to achieve a greater control of the final porosity compared to the fabrication process for bidispersed structures. According to [24,33,34], a high content of pore formers of a small size leads to an enhancement of LHP performances compared to a classical wick. The evaporator temperature, the evaporator thermal resistance and the evaporator heat transfer performance were analysed in [35]. The heat transfer performance for the evaporator with a biporous wick is enhanced by nearly $80 \%$ compared to the evaporator with a monoporous wick. Another biporous process fabrication was proposed in [36] where it was shown that the tested LHP could start up and ran correctly under different heat loads.

For a given wick thickness, the critical heat flux is not necessarily as high as expected due to preferential vapour paths leading to the breakthrough of the vapour into the compensation chamber (see for example the $1 \mathrm{~mm}$ thick wick in [30]). To prevent this issue, a bilayer wick composed by a monoporous layer at the inlet (near the compensation chamber) and a bidispersed [21] or biporous [37] layer next to the solid wall have been proposed as an interesting solution. This configuration led to a decrease in the vapour temperature [21] and in the total thermal resistance of the evaporator [37] compared to a monolayer wick (monoporous or biporous/bidispersed wicks).

Only a few numerical studies complement these experimental works. An analytical model for predicting the operating conditions of a bidispersed wick was developed in $[38,39]$. They assumed that three successive stages occur in the capillary structure. The first one corresponds to a liquid-saturated wick. The second stage begins with the occurrence of vapour within the large pores. Finally, when the capillary limit is reached, the menisci in the small pore are destroyed corresponding to the third stage. Later, the authors improved their model concerning the second stage [40] and obtained better agreement with experiments. For low heat flux, the heat transfer coefficient of the bidispersed wick is worse than the one of the monoporous wick. This phenomenon is explained by the low effective thermal conductivity and the high porosity of the bidispersed structure. They also pointed out that the spacing between large pores is an important criterion to correctly evaluate the maximum admissible heat flux.

A continuum heat and mass transfer model for a flat evaporator unit cell with a bimodal wick was presented in $[41,17]$. The model is two-dimensional and for steady-state operating condition. The model takes into account the phase change within the capillary structure considering three vaporisation modes: the evaporation occurs at the wick/groove interface and the wick is fully saturated with liquid (1st mode); then the wick is divided into two zones (a two-phase zone and a liquid-saturated zone) and the vaporisation occurs in the two-phase zone (2nd mode); and finally the wick is divided into three zones (a dry vapour zone located under the casing, a two-phase zone and a liquid-saturated zone) and the vaporisation occurs in the two-phase zone (3rd mode). The treatment of the two-phase zone is based on a radius $R^{*}$ which defines the threshold meniscus radius from which the pores become vapour. The flow within the wick is computed using Darcy's law, while only conduction is considered for the heat transfer. A heat sink term
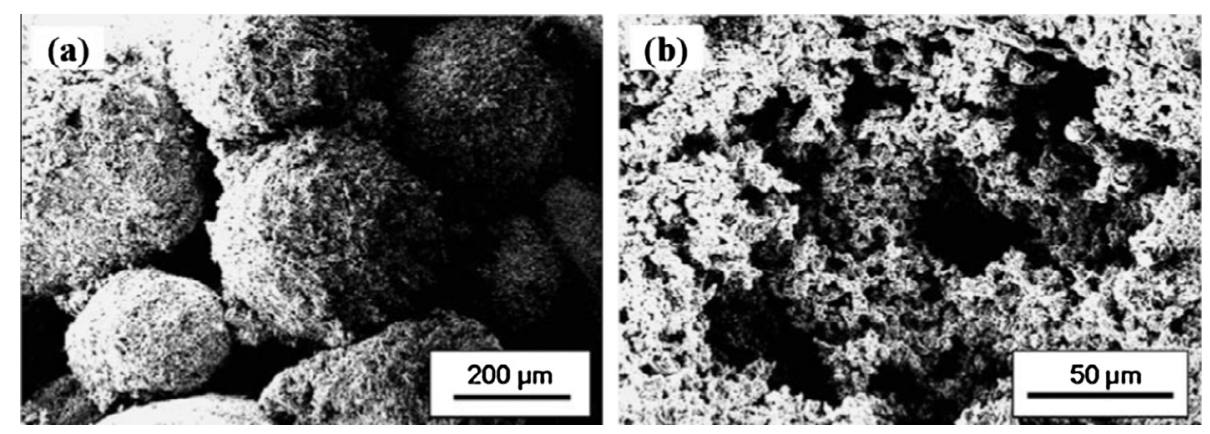

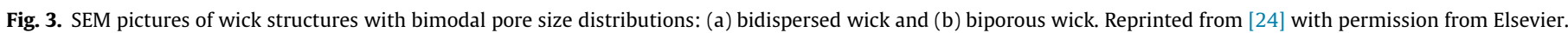


appears in the energy equation to account for evaporation in the two-phase regions. Using this model, the prediction of the casing overheating is in accordance with experimental results. An interesting aspect of this method lies in the fact that structural characteristics (pore size distribution, porosity, permeability...) of the wick are taken into account. However, the convective term in the heat transfer equation is neglected and the studied geometry is original but not usual.

A 1D mathematical model of evaporative heat transfer in a loop heat pipe (with mono and bidispersed wick structures) was developed and compared with experiments in [42]. They assumed that the wick could be spontaneously separated into three regions when the heat flux is applied. The first one is a vapour blanket, the second one is a two-phase zone and the third one is a saturated liquid zone. The liquid and vapour saturated regions were assumed to be isothermal. The liquid flow and the heat transfer were only in the radial direction, while the vapour flow was only in the axial direction. The treatment of the two-phase zone was the same as in [17]. Their results were in a general accordance with the experiment. However, the mean absolute error of the evaporator wall temperature for the monoporous wick (for the bidispersed wick respectively), for low heat flux, was about $40 \%$ ( $14 \%$ respectively). These deviations can be explained by the assumptions on the three regions which are not in agreement with the results reported in [7].

In this context, the objective of the present paper is to propose a numerical study of heat and mass transfer within a threedimensional evaporator unit cell constituted by a bimodal wick structure taking into account explicitly the bidispersed structure of the wick through a pore network model (PNM).

\section{Bidispersed structure two-scale pore network model}

Our model is based on the representation of the porous medium in term of a two-scale cubic network of pores and throats as sketched in Fig. 4. In a one-scale cubic PNM (see Fig. 4a) such as the one used in [13], the distance $a$ between two pores, referred to as the lattice spacing, also corresponds to the discretization step used to solve the governing equation and is constant, which is quite acceptable for a sintered wick. As illustrated in Fig. 2, the bidispersed capillary structure can be viewed as a network of small pores embedded in a network of larger pores, while the biporous medium can be viewed as a network of large pores embedded in a network of smaller pores. The purpose of this paper is to focus on the bidispersed wick. Two lattice spacings, denoted by $a$ for the fine network and by $b$ for the large pore network are therefore introduced for describing a bidispersed capillary structure.

As illustrated in Fig. $4 \mathrm{~b}$, the distance $b$ corresponds to the distance between two large channel intersections of the large pore network. A key aspect of the model is to interconnect properly the large pores and the fine pores. As a result, the distance between two large pores along the three main directions of the large pore network is not $b$ but the finer spacing $a$ (this is clearly illustrated in Fig. 4b). This allows connecting easily the pores of the fine network to those of the large network. As the result, the discretization step of the transport equation in the two-scale PNM is actually the fine pore lattice spacing $a$ since all the pores are in fact distributed over a Cartesian grid of step $a$. The large pore network simply corresponds to the introduction of a spatial correlation in the pore and throat size distribution along the grid of spacing $a$ so as to form the large pore network. In this respect, the discretization step is the same as in the one scale network.

In pore network models, the capillary pressure is expressed as a function of the throat size using the Laplace-Young equation (see Eq. (19) below). Generally, the pore size distribution (PSD) is given in literature. However, the PSD, obtained for example by mercury porosimetry, actually corresponds to throat size distributions (TSD). Thus, the throat diameters in the PNM must correspond to the "pore size distribution" obtained experimentally. In addition to the actual TSD, we want our network to have the same porosity as the real wick we are interested in. How to achieve this goal, i.e. how to specify the porosity and the PSD and TSD of the PNM from available experimental data for a given wick, is described in Appendix A for a one-scale PNM (monoporous wick) and in Appendix B for the two-scale PNM (bidispersed wick).

As explained in Appendix B, the main unknowns for the construction of the bidispersed network are the lattice spacing $b$ of the large network, the porosity $\varepsilon_{L}$ of the large network, the distribution of the large pore diameter $d_{p, L}$ and the one of the small pore diameter $d_{p, s}$, noting that the size of large pores, small pores and the size of the small pore clusters are generally available from the experimental works. These experimental data permit to determine an approximate number of large pores for the PNM to be representative of the real sample. In this respect, it is important to note that the large pore network controls the vapour preferential paths within the wick allowing the vapour to escape from

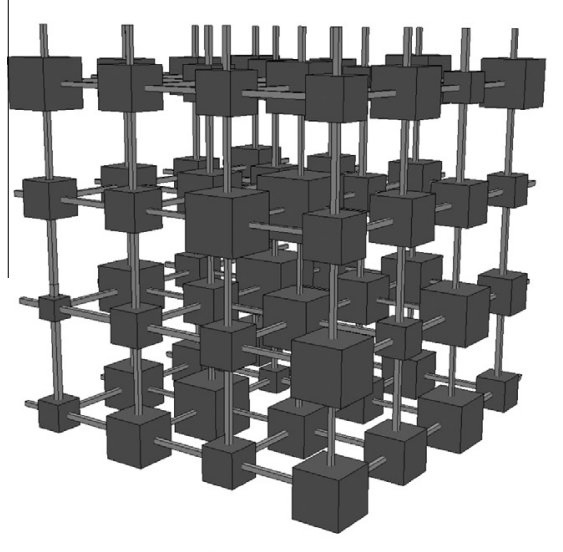

(a)

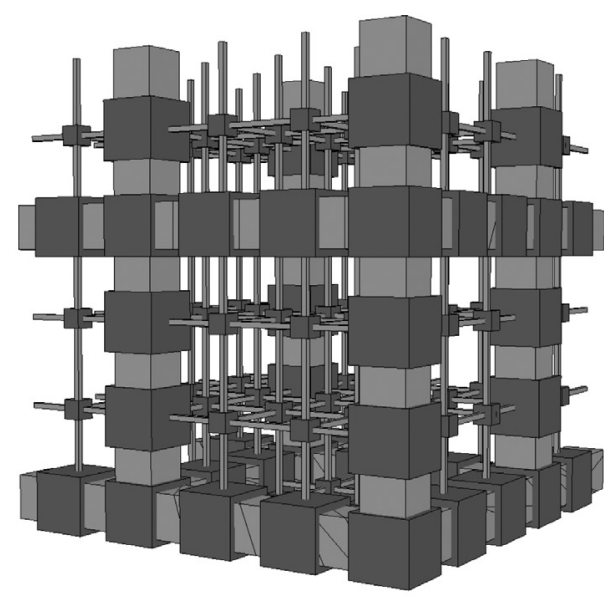

(b)

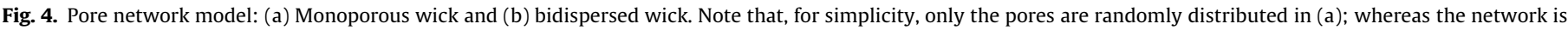

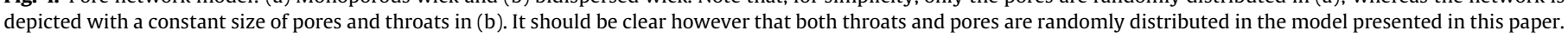


beneath the casing. Thus, based on the geometrical consideration explained in Appendix B, $b, \varepsilon_{L}, d_{p, L}$ and $d_{p, S}$ are determined and used for the construction of the two-scale pore network.

\section{Numerical model}

\subsection{Governing equations}

As in [13], a mesoscale approach is used. This means that capillary effects are handled as in classical pore network model whereas the temperature and pressure fields are computed according to a mean field approach. For this reason, this mesoscale model is referred to as a mixed pore network model. Here, only the main governing equations and adaptations of the model for the bidispersed structure are presented. For more details see [7]. Subscript $i$ denotes the liquid $l$ or the vapour $v$ phase, while subscript $j$ corresponds to the large network $L$ or the small network $S$.

Heat transfer through the metallic casing occurs only by conduction.

$\nabla \cdot\left(k_{c} \nabla T\right)=0$

where $k_{c}$ is the thermal conductivity of the casing.

Heat transfer occurs by convection and conduction within the wick,

$\left(\rho c_{p}\right)_{i} \mathbf{u}_{i} \cdot \nabla T=\nabla \cdot\left(k_{i, j}^{*} \nabla T\right)$

where $\mathbf{u}_{i}$ is the velocity of phase $i$ and $k_{i, j}^{*}$ is the effective thermal conductivity of network $j$ when the pores are occupied by phase $i$. The effective thermal conductivity of the wick depends on the solid matrix conductivity, the fluid thermal conductivity and the porosity. The arithmetic average between the classical arrangement of the phases in parallel and in series is used:

$k_{i, j}^{*}=\frac{1}{2}\left(\varepsilon_{j} k_{i}+\left(1-\varepsilon_{j}\right) k_{w}+\frac{k_{i} k_{w}}{\varepsilon_{j} k_{w}+\left(1-\varepsilon_{j}\right) k_{i}}\right)$

where $k_{w}$ is the thermal conductivity of the solid matrix.

Darcy's law (Eq. (4)) is combined with the mass conservation equation (Eq. (5)) for determining the pressure field within the wick.

$\mathbf{u}_{i}=-\frac{K_{j}}{\mu_{i}} \nabla P$

$\nabla \cdot\left(\rho_{i} \mathbf{u}_{i}\right)=0$

The vapour phase is supposed to be a slightly compressible ideal gas whereas the liquid phase is supposed to be incompressible.

\subsection{Boundary condition}

The heat load $Q$ is applied at the external surface of the metallic casing (Eq. (6)). Energy conservation (Eq. (7)) and no flow conditions (Eq. (8)) are imposed at the casing/wick interface. A convective boundary condition is used at the casing/groove interface (Eq. (9)). The pressure $P_{c c}$ and the temperature $T_{c c}$ are imposed at the inlet of the wick. They are supposed to be equal to the compensation chamber pressure and temperature (Eqs. (10) and (11)). The groove temperature $T_{g}$ is taken at the saturation temperature corresponding to the groove pressure $P_{g}$ (Eq. (12)). The groove pressure $P_{g}$ is computed using the loop model presented in [7] (Eq. (13)). Spatially periodic boundary conditions are imposed on the lateral sides of computational domain.

Casing external surface:

$$
\left(k_{c} \nabla T\right) \cdot \mathbf{n}=Q
$$

Wick/casing interface:

$$
\begin{aligned}
& \left(-k_{i, j}^{*} \nabla T\right) \cdot \mathbf{n}=\left(-k_{c} \nabla T\right) \cdot \mathbf{n} \\
& \nabla P \cdot \mathbf{n}=0
\end{aligned}
$$

Groove/casing interface:

$\left(k_{c} \nabla T\right) \cdot \mathbf{n}=h_{g}\left(T-T_{g}\right)$

Wick inlet:

$T_{c c}=T_{s a t}-\Delta T_{s u b}$

$P_{c c}=P_{\text {sat }}\left(T_{\text {sat }}\right)$

Groove:

$$
\begin{aligned}
& T_{g}=T_{\text {sat }}\left(P_{g}\right) \\
& P_{g}=P_{c c}+\Delta P_{\text {loop }}
\end{aligned}
$$

$\mathbf{n}$ is the interface normal unit vector. The heat transfer coefficient $h_{g}$ is computed using a relation presented in [43]. $\Delta T_{\text {sub }}$ is a possible subcooling of the liquid at the wick inlet. $\Delta P_{\text {loop }}$ is the pressure drop in the other components of the loop determined as presented in [7].

The liquid-vapour interface is located within the wick and/or at the wick/groove interface. Energy conservation (Eq. (14)) and temperature continuity (Eqs. (15) and (16)) are imposed at the menisci located within the wick. Energy conservation (Eq. (17)) is imposed at the wick/groove interface if the considered wick point is in liquid state; otherwise a convective boundary condition is used (Eq. (18)). The Clausius-Clapeyron relationship is used to link the temperature and the vapour pressure along the liquid-vapour interface, i.e. at each meniscus present in the system.

Liquid-vapour interface within the wick:

$$
\begin{aligned}
& \left(-k_{l, j}^{*} \nabla T\right) \cdot \mathbf{n}-\left(-k_{v, j}^{*} \nabla T\right) \cdot \mathbf{n}=\rho_{l} h_{l v} \mathbf{u}_{l} \cdot \mathbf{n} \\
& \rho_{v} \mathbf{u}_{v} \cdot \mathbf{n}=\rho_{l} \mathbf{u}_{l} \cdot \mathbf{n} \\
& T_{l}=T_{v}=T_{s a t}\left(P_{v}\right)
\end{aligned}
$$

Liquid-vapour interface at the wick/groove boundary:

$$
\left(-k_{l, j}^{*} \nabla T\right) \cdot \mathbf{n}=\rho_{l} h_{l v} \mathbf{u}_{l} \cdot \mathbf{n}
$$

Vapour-vapour interface at the wick/groove boundary:

$$
\left(k_{v, j}^{*} \nabla T\right) \cdot \mathbf{n}=h_{g}\left(T-T_{g}\right)
$$

$h_{l v}$ is the latent heat of vaporisation.

The Laplace law (Eq. (19)) is used to determine the maximum pressure difference that can exist between the liquid and the vapour across a meniscus for a perfectly wetting fluid.

$\Delta P_{\text {cap }, \max }=\frac{4 \sigma}{d}$

where $d$ is the diameter of the considered throat and $\sigma$ is the surface tension.

\section{Method of solution}

An iterative home-made code written in Fortran90 was developed in order to solve Eqs. (1)-(19). A finite volume method [44] is used to discretize the governing equations with grid points centred on pores. As mentioned before, the equations are discretized over the finer grid of step $a$ containing both large and small pores. An upwind scheme is used for the convective term in the energy equation (Eq. (2)). The interface thermal conductivity is set as a compound value of the conductivities of the two materials at the wick-casing boundary. For the bidispersed case, permeabilities $K_{L}$ and $K_{S}$ and porosities $\varepsilon_{L}$, and $\varepsilon_{S}$ are defined for the large pore network and the small pore network respectively. Permeability 


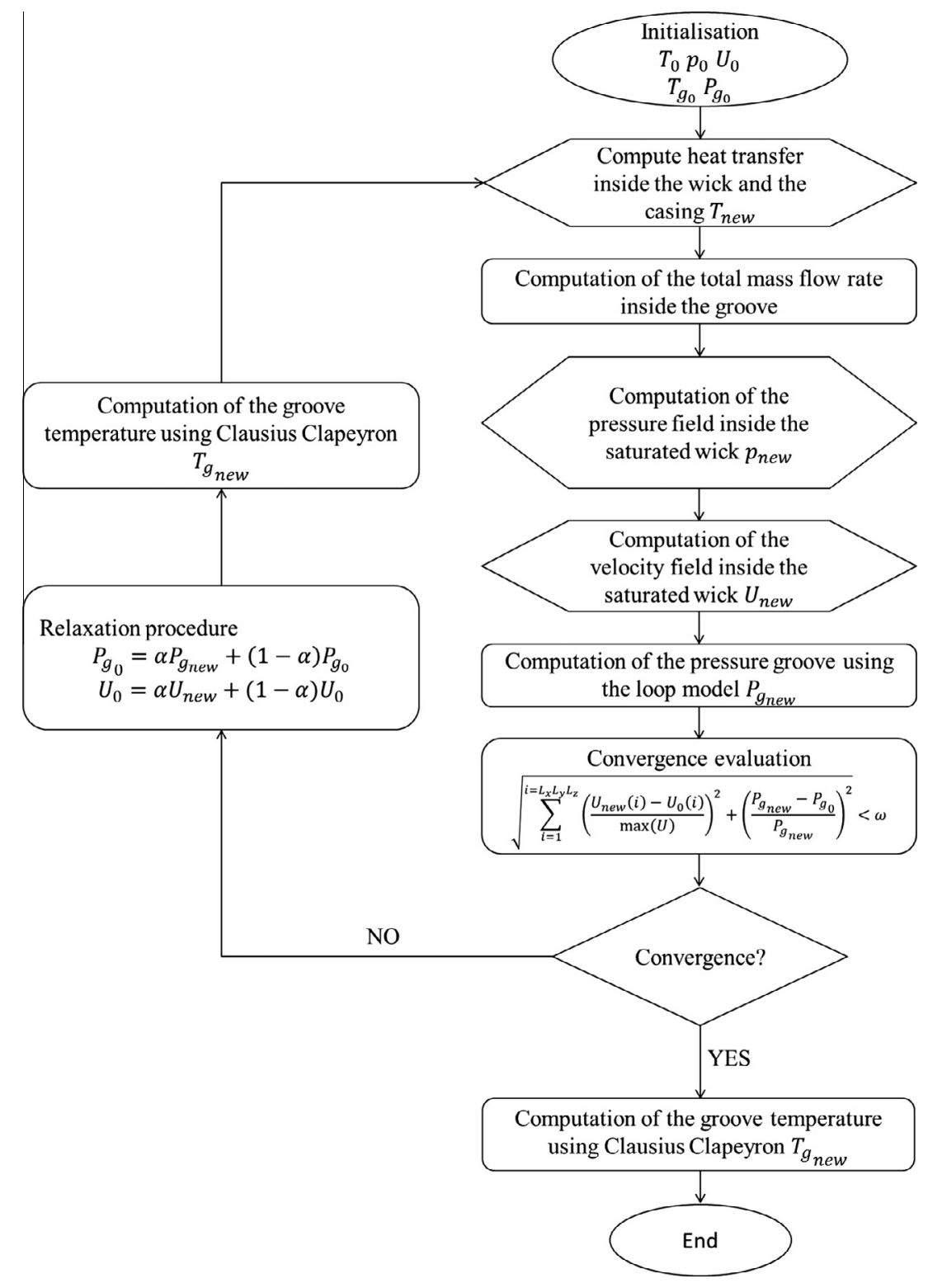

Fig. 5. Computational chart for the case with a liquid saturated wick. Reprinted from [7] with permission from Elsevier.

and porosity of a link connecting a small pore and a large pore are taken as compound values between the two considered nodes (using harmonic means).

For low heat flux, no vapour occurs within the wick. Solving the problem is then easy. The corresponding algorithm is summarized in Fig. 5. When $T_{\text {sup }}$, the difference between the temperature of the liquid under the casing and the saturated temperature, is greater than a fixed threshold (usually between 2 and $4 \mathrm{~K}$ and taken here at $4 \mathrm{~K}$ ), vapour forms within the wick and the unsaturated case has to be solved using the algorithm summarized in Fig. 6.

Once all equations are solved, the pressure difference $\Delta P$, defined as $\Delta P=P_{v}-P_{l}$ is computed for each meniscus present in the two-scale network. This value is compared for each meniscus to the capillary pressure threshold defined by Eq. (19). If $\Delta P>\Delta P_{\text {cap }}$, the meniscus is then displaced into the adjacent pore and all the equations are solved again. The interface is considered as stable when the condition $\Delta P<\Delta P_{\text {cap }}$ is satisfied for each meniscus.

\section{Results}

\subsection{Model validation}

In this section, simulations are compared to experimental results available in Lin et al. [32]. These authors studied one monoporous wick (called sample $A$ in [32]) and three bidispersed wicks (called sample B, C and D in [32]). Sample A and sample D are numerically studied in this paper. The geometry dimensions, as well as the porous medium properties, the loop dimensions and the working fluid are the same as the ones used in the experiment of Lin et al. [32]. Unknown parameters not specified in [31] are deduced or taken to be as much as possible close to realistic values based on other studies by the same group ([24,33,37,42,45]). Note that the grooves are manufactured within the wick. All the properties used in the simulations are summarized in Table 1.

Of primary interest is the quantification of the evaporator thermal performance, i.e. the conductance $h_{e v}$ (also called heat transfer coefficient), 


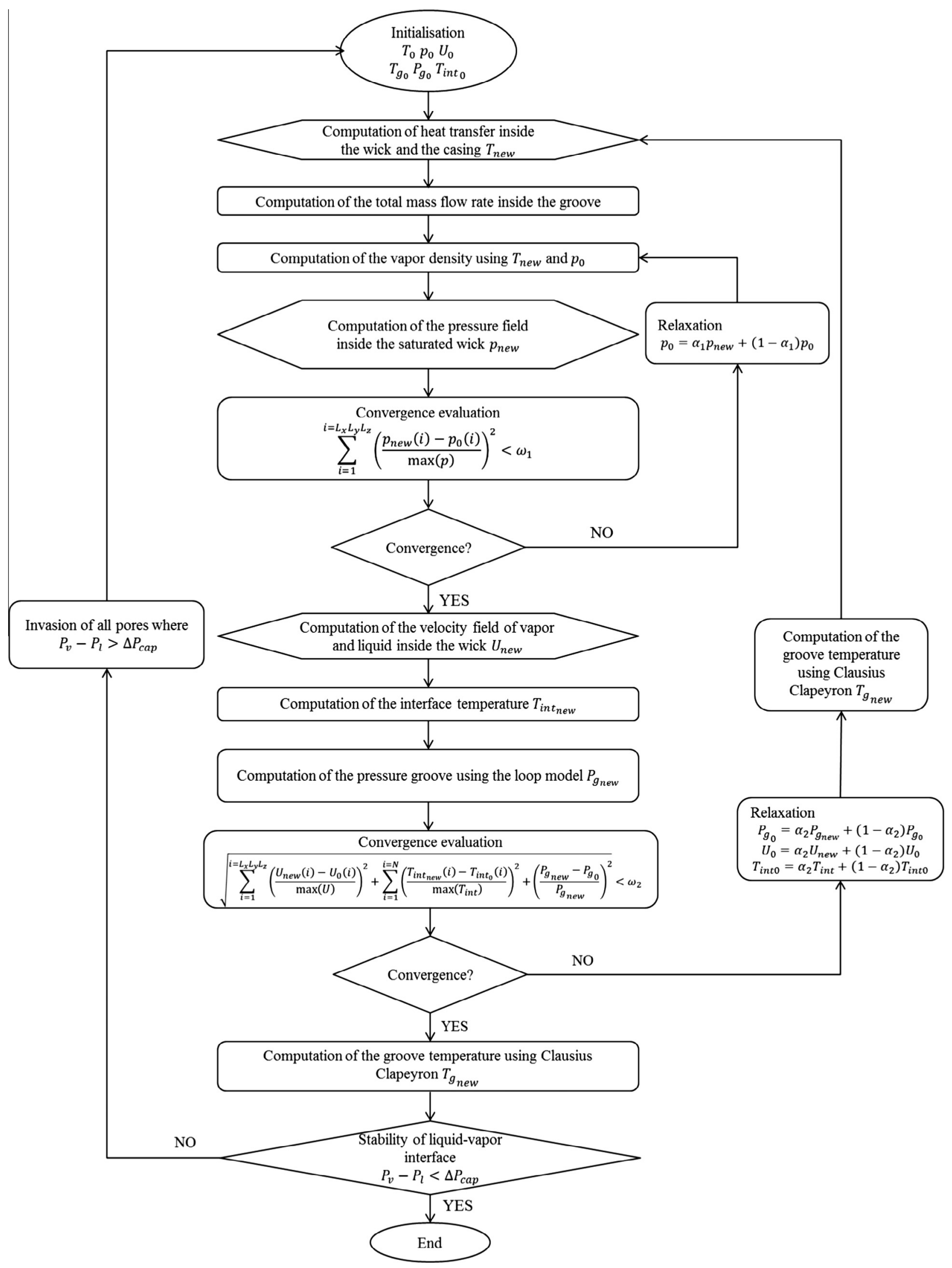

Fig. 6. Computational chart for the case with an unsaturated wick. Reprinted from [7] with permission from Elsevier. 
Table 1

Porous material properties, fluid properties, geometrical dimensions and loop dimensions used in simulations.

\begin{tabular}{|c|c|c|c|c|}
\hline \multicolumn{5}{|l|}{ Evaporator dimensions } \\
\hline \multicolumn{3}{|c|}{ Evaporator active length (mm) } & & 40 \\
\hline \multicolumn{3}{|c|}{ Evaporator outer $(\mathrm{mm}) /$ inner $(\mathrm{mm})$ diameters } & & $15.5 / 12.5$ \\
\hline \multicolumn{3}{|c|}{ Wick outer $(\mathrm{mm}) /$ inner $(\mathrm{mm})$ diameters } & & $12.5 / 9$ \\
\hline \multicolumn{3}{|c|}{ Number of grooves/length of grooves (mm) } & & $8 / 40$ \\
\hline \multirow[t]{2}{*}{ Wick properties (Nickel) } & \multirow{2}{*}{\multicolumn{2}{|c|}{$\begin{array}{l}\text { Sample A } \\
\text { Monoporous wick }\end{array}$}} & \multirow{2}{*}{\multicolumn{2}{|c|}{$\begin{array}{l}\text { Sample D } \\
\text { Bidispersed wick }\end{array}$}} \\
\hline & & & & \\
\hline \multirow{6}{*}{$\begin{array}{l}\text { Thermal conductivity }(\mathrm{W} / \mathrm{m} / \mathrm{K}) \\
\text { Throat diameter range }(\mu \mathrm{m}) \\
\text { Cluster diameter }(\mu \mathrm{m}) \\
\text { Throat diameter p.d.f } \\
\text { Lattice spacing }(\mathrm{mm})\end{array}$} & & \multicolumn{2}{|l|}{91} \\
\hline & \multirow{2}{*}{\multicolumn{2}{|c|}{$6 \pm 4$}} & \multirow{2}{*}{\multicolumn{2}{|c|}{$\begin{array}{l}1.2 \pm 1.1 \text { and } 13 \pm 6 \\
20-62\end{array}$}} \\
\hline & & & & \\
\hline & \multicolumn{2}{|l|}{ Normal } & \multicolumn{2}{|l|}{ Normal } \\
\hline & \multicolumn{2}{|l|}{$a=0.0847$} & \multicolumn{2}{|l|}{$a=0.0847$ and $b=0.3388$} \\
\hline & Experiment & Numerical & Experiment & Numerical \\
\hline Porosity & 0.743 & 0.747 & 0.768 & 0.764 \\
\hline Permeability $\left(\mathrm{m}^{2}\right)$ & $2.3 \times 10^{-12}$ & $1 \times 10^{-12}$ & $7.7 \times 10^{-12}$ & $6.8 \times 10^{-12}$ \\
\hline \multicolumn{5}{|l|}{ Casing property (Aluminium) } \\
\hline \multicolumn{2}{|l|}{ Thermal conductivity $(\mathrm{W} / \mathrm{m} / \mathrm{K})$} & 205 & & \\
\hline \multicolumn{2}{|l|}{ Fluid property (Ammonia) } & Liquid & & Vapour \\
\hline \multirow{6}{*}{\multicolumn{2}{|c|}{$\begin{array}{l}\text { Thermal conductivity }(\mathrm{W} / \mathrm{m} / \mathrm{K}) \\
\text { Dynamic viscosity }(\mathrm{Pa} \mathrm{s}) \\
\text { Specific heat capacity }(\mathrm{J} / \mathrm{kg} / \mathrm{K}) \\
\text { Latent heat of vaporisation }(\mathrm{J} / \mathrm{kg}) \\
\text { Interfacial tension }(\mathrm{N} / \mathrm{m}) \\
\text { Liquid density }\left(\mathrm{kg} / \mathrm{m}^{3}\right)\end{array}$}} & 0.52912 & & 0.024365 \\
\hline & & $156 \times 10^{-6}$ & & $9.63 \times 10^{-6}$ \\
\hline & & 4678.7 & & 2841.3 \\
\hline & & $1,225,580$ & & \\
\hline & & 0.029589 & & \\
\hline & & 624.46 & & \\
\hline \multicolumn{5}{|c|}{ Geometrical dimensions ( $\mathrm{mm}$ ) (see Fig. 1c for definitions) } \\
\hline \multicolumn{2}{|l|}{$L_{x}$} & & & 5 \\
\hline \multicolumn{2}{|l|}{$L_{y}$} & & & 3.25 \\
\hline \multicolumn{2}{|l|}{$L_{z}$} & & & 3 \\
\hline \multicolumn{2}{|l|}{$L_{x v}$} & & & 0.5 \\
\hline \multicolumn{2}{|l|}{$L_{y w}$} & & & 0.75 \\
\hline \multicolumn{2}{|l|}{$L_{y g}$} & & & 1 \\
\hline \multicolumn{5}{|l|}{ Loop dimension } \\
\hline Length $(\mathrm{mm}) /$ inner diameter $(\mathrm{m}$ & & & & $470 / 5$ \\
\hline Length $(\mathrm{mm}) /$ inner diameter $(\mathrm{m}$ & & & & $580 / 4$ \\
\hline Length $(\mathrm{mm}) /$ inner diameter $(\mathrm{m}$ & & & & $800 / 5$ \\
\hline
\end{tabular}

$$
h_{e v}=\frac{Q}{T_{c, \max }-T_{g}}
$$

where $Q$ is the applied heat load in $\mathrm{W} / \mathrm{cm}^{2}, T_{c, \max }$ is the maximal temperature of the casing and $T_{g}$ is the vapour temperature within the removal channels, i.e. the vapour grooves. The overheating of the casing $\Delta T_{c}$, defined as the casing excess temperature, is the difference between the casing temperature $T_{c, \max }$ and the saturation temperature within the groove $T_{g}$,

$$
\Delta T_{c}=T_{c, \max }-T_{g}
$$

The variations of the evaporator conductance and the overheating of the casing as a function of the heat flux are shown in Figs. 7 and 8 . The numerical conductance is greater than the one measured experimentally, whereas the overheating of the casing is underestimated. Note however that several unknown parameters were estimated, such as the compensation chamber temperature, as well as the fin and groove dimensions and thus could explain the observed differences. Nevertheless, the trend is respected and a general good agreement is found. Our conclusion is that the agreement between the present model and the experimental results of Lin et al. [32] can be considered as sufficiently good to use with confidence our pore network model for studying bimodal capillary structures within a capillary evaporator. Moreover, this kind of model allows quantifying several parameters, such as the liquid-vapour phase distribution, the vapour saturation as well as the vapour flow rate, which are not easily obtained experimentally, while they are often key elements to explain the behaviour of the evaporator performance.

\subsection{Evaporator heat transfer coefficient and vapour saturation}

The evaporator heat transfer coefficient as a function of the applied heat load is shown in Fig. 7. At low heat flux, the monoporous evaporator has better thermal performance than the bidispersed one. However, the evaporator heat transfer coefficient of the monoporous sample decreased rapidly after $10 \mathrm{~W} / \mathrm{cm}^{2}$. The trend of the conductance for the bidispersed sample is different compared to the monoporous wick. From $5 \mathrm{~W} / \mathrm{cm}^{2}$ to $25 \mathrm{~W} / \mathrm{cm}^{2}$, the heat transfer increases from about $1.5 \mathrm{~W} / \mathrm{cm}^{2} / \mathrm{K}$ to $3 \mathrm{~W} / \mathrm{cm}^{2}$ / $K$. The difference between these trends can be explained by considering the liquid-vapour phase distribution within the wick similarly as in [7]. For this purpose, the liquid-vapour phase distributions for different heat fluxes are depicted in Fig. 9 for both the bidispersed and the monoporous structures.

The fraction of pores right under the casing occupied by vapour in the plane located right under the casing and the vapour saturation within the wick are investigated to explain the conductance behaviour (Fig. 10). As can be seen from Figs. 9 and 10, the monoporous wick is rapidly invaded by vapour. At low heat flux, $60 \%$ of the wick are already invaded by vapour and $70 \%$ of the wick/casing interface are occupied by vapour pores. By contrast, 


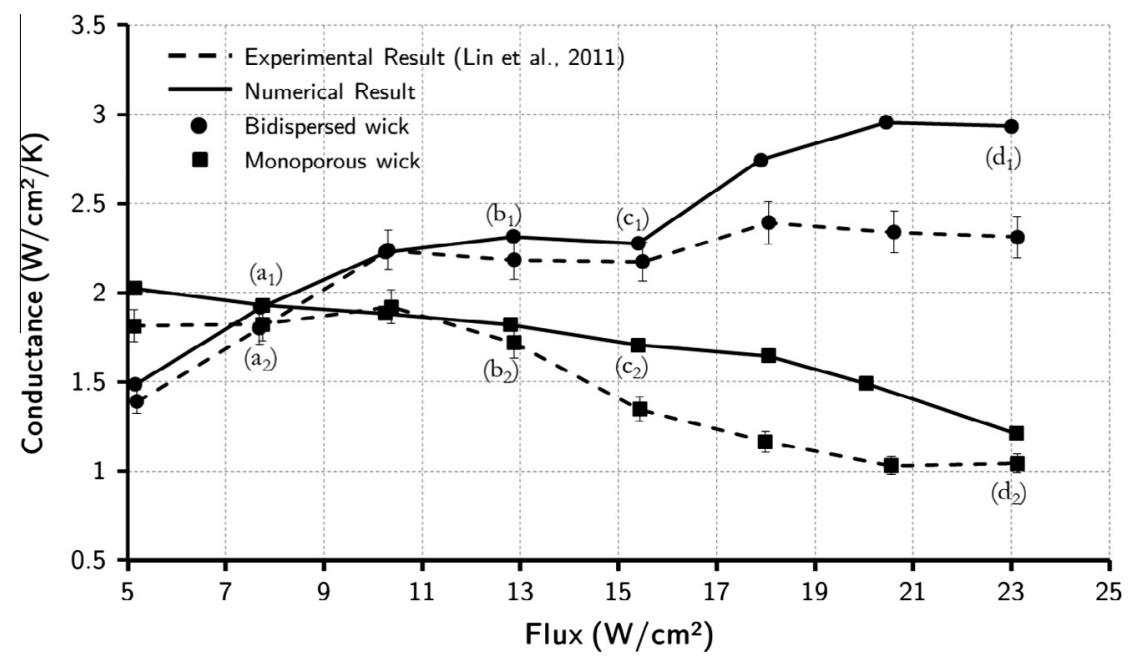

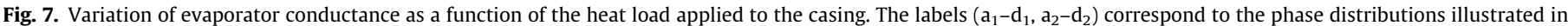
Fig. 9.

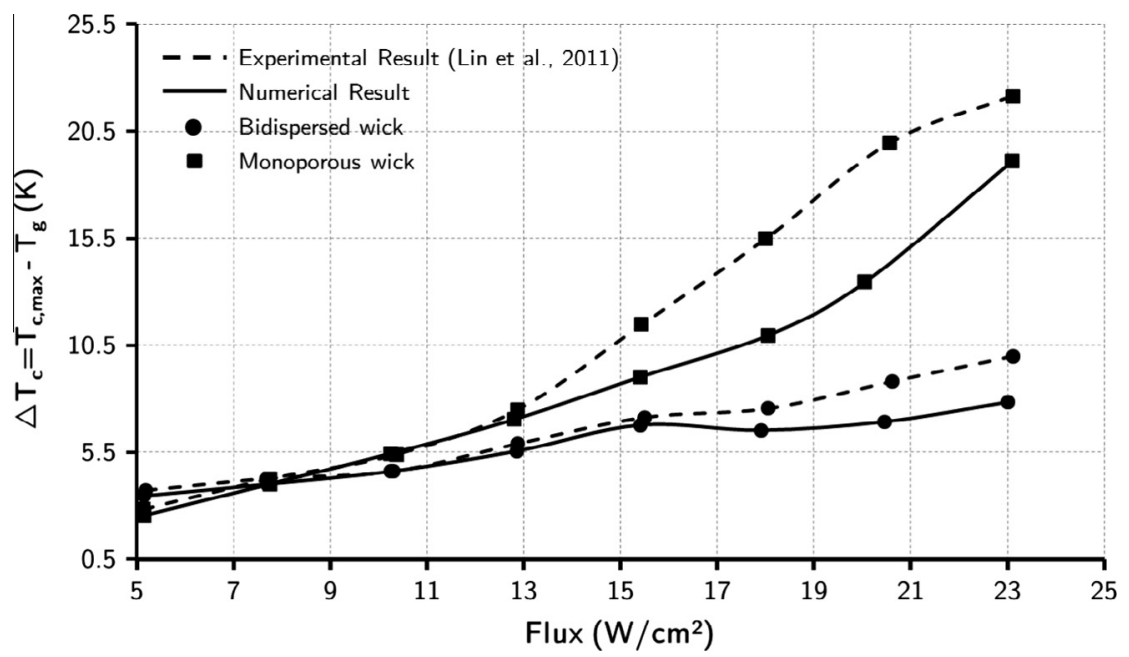

Fig. 8. Variation of vapour $\Delta T_{c}$ as a function of the heat load applied to the casing.

the bidispersed wick vapour saturation is less than $5 \%$ and the fraction of pores occupied by vapour at the wick/casing interface is less than $30 \%$.

Contrary to the monoporous wick, the liquid phase is predominant under the casing for the bidispersed wick, thus ensuring a better thermal performance in accordance with the results and discussion presented in [7]. Indeed, as discussed in [13] three evaporator regimes can be distinguished with the increase in the heat load. The first regime corresponds to the low heat loads where the wick is saturated, i.e. there is no meniscus recession within the wick and the conductance is constant. During this regime, the evaporator has relatively poor thermal performances. The second regime occurs when vapour begins to invade the wick. During this regime, a two-phase zone exists under the casing, i.e. the liquid and the vapour phases are both in contact with the casing. This second regime thus corresponds to the occurrence of a two-phase zone under the casing and can be itself divided into three parts qualitatively described as follows: the first one corresponds to the increase in the conductance; the second part corresponds to the best performance of the evaporator (the conductance reaches a plateau); the last part corresponds to the beginning of the decrease in the thermal performance when the vapour at the wick/casing interface exceeds a certain fraction of the wick/casing surface, i.e. the vapour becomes predominant in this zone. Finally, the last and third regime corresponds to a rapid fall in the conductance and begins when the layer of pores under the casing is fully occupied by vapour. Note that the upper and lower bonds of the fraction of pores occupied by vapour under the casing which delimit each regime depend on the geometry and properties of the wick and the casing.

As already mentioned, the monoporous evaporator has better thermal performance than the bidispersed one at low heat fluxes. Under $6.7 \mathrm{~W} / \mathrm{cm}^{2}$, the bidispersed wick is still full of liquid (regime 1) (Fig. 10), which as recalled above corresponds to relatively poor evaporator performances whereas the monoporous wick is already invaded by vapour, and thus in the best regime (regime 2 ). Consistently, the heat transfer performance of the bidisperse wick is less good than the monoporous wick one. Beyond $6.7 \mathrm{~W} / \mathrm{cm}^{2}$, the bidispersed wick operates in the second regime according to the conductance behaviour. The variation of the fraction of vapour pores under the casing is in good agreement with this observation. Indeed, the conductance increases with the heat load until $10 \mathrm{~W} /$ $\mathrm{cm}^{2}$ and seems to stabilize (according to experimental data) corresponding respectively to the first and second parts of the second regime described in [7]. The conductance of the monoporous wick is almost constant until $10 \mathrm{~W} / \mathrm{cm}^{2}$, corresponding to a fraction of 


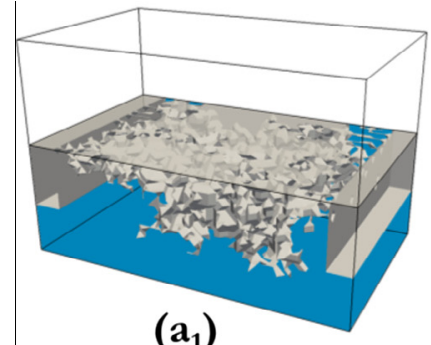

$\left(a_{1}\right)$

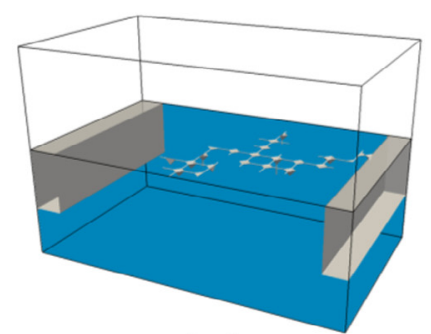

$\left(a_{2}\right)$
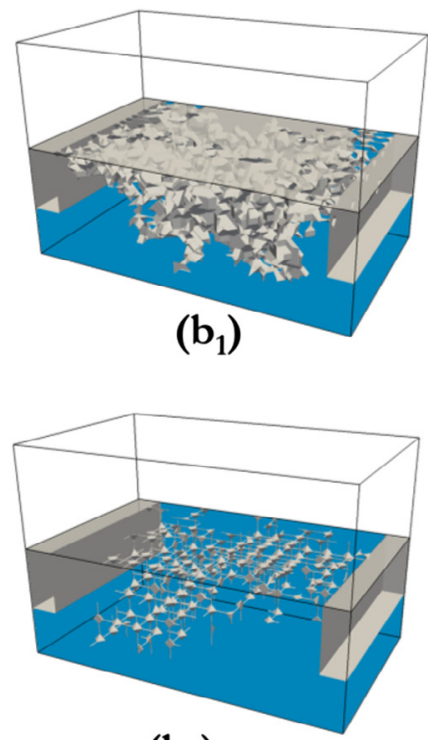

$\left(b_{2}\right)$
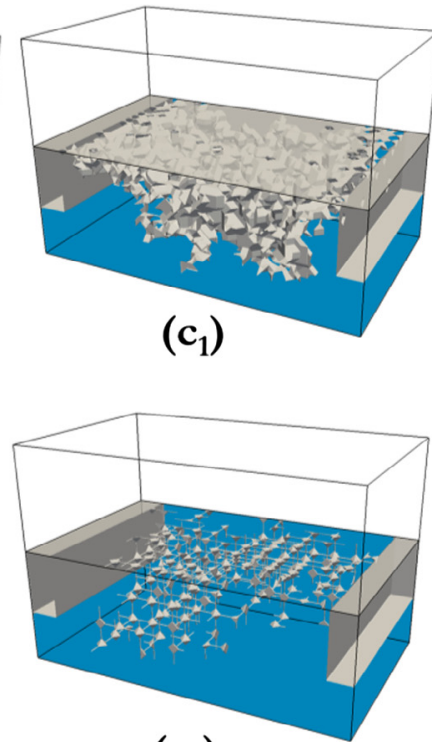

$\left(c_{2}\right)$
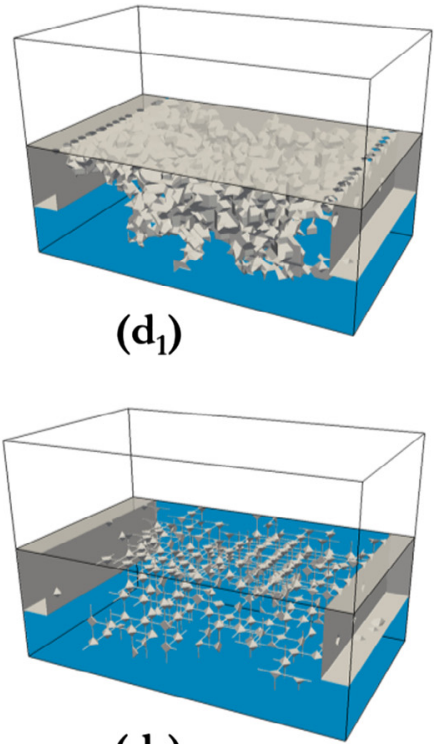

$\left(d_{2}\right)$

Fig. 9. Pore network numerical visualisations of vapour and liquid phase distribution in the evaporator unit cell for the same fluxes in the monoporous and bidispersed wick. Vapour phase is in grey and liquid phase is in blue. Figures $\left(a_{1}\right)$ from $\left(d_{1}\right)$ correspond to the bidispersed wick structure and Figures $\left(a_{2}\right)$ from $\left(d_{2}\right)$ refer to the monoporous wick structure. $\left(a_{1}\right)$ and $\left(a_{2}\right)$ are results at $7.7 \mathrm{~W} / \mathrm{cm}^{2} ;\left(b_{1}\right)$ and $\left(b_{2}\right)$ are results at $12.8 \mathrm{~W} / \mathrm{cm}^{2} ;\left(c_{1}\right)$ and $\left(c_{2}\right)$ are results at $15.35 \mathrm{~W} / \mathrm{cm}^{2}$ and $\left(\mathrm{d}_{1}\right)$ and $\left(\mathrm{d}_{2}\right)$ are results at $23 \mathrm{~W} / \mathrm{cm}^{2}$. $(F$ or interpretation of the references to colour in this figure legend, the reader is referred to the web version of this article.)

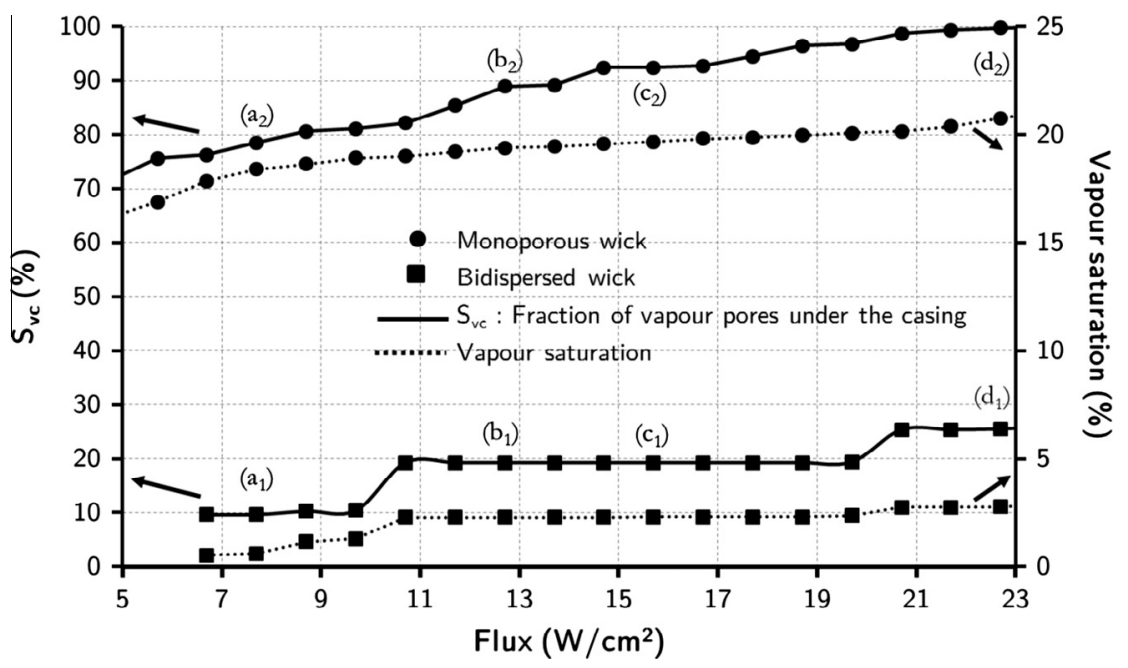

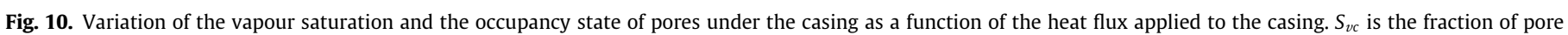
occupied by vapour right under the casing. The labels $\left(a_{1}-d_{1}, a_{2}-d_{2}\right)$ correspond to the phase distributions illustrated in Fig. 9 .

pores under the casing lower than $80 \%$, i.e. the wick operates in the second regime. When more than $80 \%$ of the wick/casing interface is invaded by vapour, the conductance decreases. The vapour becomes largely predominant under the casing thus adding a thermal resistance which induces the decrease of evaporator performance.

The best performance of evaporator is thus well correlated with the occurrence of a two-phase zone under the casing as expected. In brief, the bimodal capillary structure creates preferential paths for the vapour, thus keeping a two-phase zone in contact with the casing for a larger range of heat flux.

\subsection{Evaporator wall temperature}

The compensation chamber temperature is an input in our model (Eq. (10)) which conditions the overall evaporator temperature field. Unfortunately, this value is not reported in Lin et al. [32].
The compensation chamber (CC) temperature was fixed at $283.15 \mathrm{~K}$ in our simulations. With this temperature for the CC, the maximal temperature of the evaporator, located at the casing external surface, obtained numerically, was lower than the one obtained experimentally. Temperature fields for heat load equal to $12.8 \mathrm{~W} / \mathrm{cm}^{2}$ are given for the monoporous and the bidispersed wick in Appendix C (see Fig. C1). Instead of fitting this temperature so as to obtain comparable values with the experiment as regards the maximal temperature, we simply consider the overheating of the casing $\Delta T_{c}$. It is expected that the computed $\Delta T_{c}$ should be comparable to the experimental one. As can be seen in Fig. 8, this is indeed the case, especially for the bidispersed wick.

For low heat load, i.e. under $6.7 \mathrm{~W} / \mathrm{cm}^{2}$, the overheating of the casing for the bidispersed wick is greater than the one of the monoporous wick as in the experiments. This trend is in accordance with the conductance behaviour. Indeed, the monoporous wick operates in the second regime (invasion of vapour) and has better thermal 


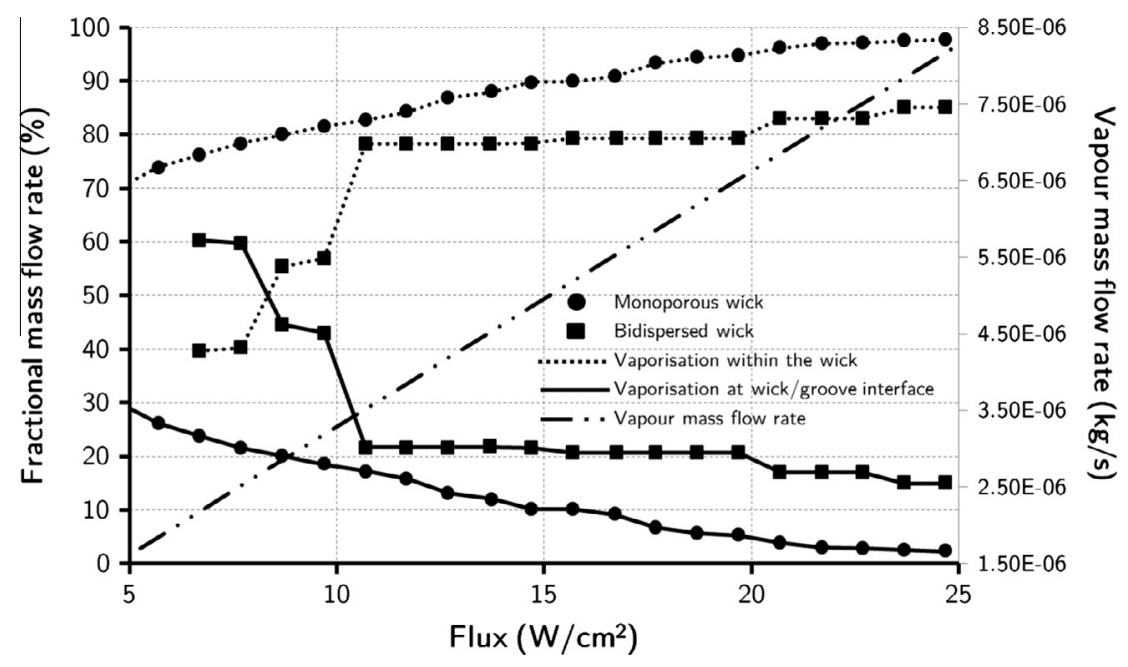

Fig. 11. Variation of vapour mass flow rate partition and vapour mass flow rate as a function of the heat flux applied to the casing.

performance than the bidispersed one which is saturated with the liquid and operates in the first regime.

Once the vapour has invaded the wick, the overheating of the bidispersed wick increases slowly; whereas the overheating of the monoporous one rises rapidly. This trend is well reproduced by the simulations. With the increase of the heat load, the fraction of vapour pores under the casing is greater than $80 \%$ for the monoporous sample (Fig. 10). The vapour induces a higher thermal resistance and thus the marked increase of the casing overheating. The large network of the bidispersed wick ensures paths for the vapour, thus facilitating the vapour escape. As a result, the vapour does not invade the layer of pores right under the casing and this prevents the overheating of the casing. Moreover, as pointed out by others author ([20]), the overheating of the casing rises quickly for a low $k_{v}^{*}$, whereas the overheating of the casing is not the operating limit for a more conductive wick, i.e. for high $k_{v}^{*}$. The effective thermal conductivity depends on the porosity (Eq. (3))and $k_{v}^{*}$ is higher for a lower porosity. Indeed, the porosity of the bidispersed wick is greater than the one of the monoporous wick. The calculated vapour effective thermal conductivities are equal to $26.2 \mathrm{~W} / \mathrm{m} / \mathrm{K}$ and $14.2 \mathrm{~W} / \mathrm{m} / \mathrm{K}$ respectively. As explained at the beginning of the paragraph, this difference in the value of $k_{v}^{*}$ induces a slower rising of the overheating for the bidispersed wick.

\subsection{Vaporisation partition}

The mass flow rate of vapour feeding the vapour groove is shown as a function of the heat flux applied to the casing in Fig. 11. This mass flow rate is divided into the mass flow rate which results from the liquid vaporisation at the wick/groove interface and the mass flow rate which results from the vaporisation within the wick. For a given heat flux, the mass flow rate of vapour is the same for the monoporous and the bidispersed wick. Hence, the two curves are exactly superimposed. For low heat flux, i.e. below than $7.7 \mathrm{~W} / \mathrm{cm}^{2}$, the vapour essentially comes from the vaporisation process at the wick/groove interface for the bidispersed wick, whereas already $70-80 \%$ of the mass flow rate come from the vaporisation within the wick for the monoporous wick. Beyond $7.7 \mathrm{~W} / \mathrm{cm}^{2}$, the vapour which feeds the groove of the bidispersed evaporator mostly comes from the vaporisation process within the capillary structure. Actually, the trend shown around $7.7 \mathrm{~W} /$ $\mathrm{cm}^{2}$ is correlated with the beginning of regime 2 as defined in [7]. From $10 \mathrm{~W} / \mathrm{cm}^{2}$, the mass flow rate distribution is almost similar for both wicks: around $80-100 \%$ of the vapour feeding the grooves come from the vaporisation within the wick.

\section{Conclusions}

Pore network models of a LHP/CPL evaporator were presented for a bidispersed and a monoporous wick structures. Simulations were compared with experimental data. The model was validated from the consideration of the steady-state evaporator thermal performance, i.e. its conductance, and the overheating of the evaporator. Comparisons with experimental results show a good agreement for both the monoporous and the bimodal capillary structures. The observed difference can be attributed to the unknown parameters (compensation chamber temperature, grooves dimensions...) which were deduced from others experimental studies. However, the trend of $h_{e v}$ and $\Delta T_{c}$ are respected, and the mixed pore network model permits to explain their behaviour based on the liquidvapour phase distribution within the wick. The vapour mass flow rate was also investigated.

The presence of a two-phase zone, i.e. the coexistence of liquid and vapour in the same zone under the casing is positively correlated with the best evaporator thermal performance and prevents the overheating of the casing. At low heat flux, the vaporisation of the bidispersed wick takes place at the wick-groove interface only and the thermal performance is lower than for the monoporous wick which is already invaded by vapour, i.e. the vaporisation also takes place within the wick. For a higher heat load, the bidispersed wick reaches better thermal performance than the monodispersed wick. The first row of pores under the casing is almost full of vapour for the monoporous capillary structure, inducing an additional thermal resistance and a significant increase in the casing overheating. On the contrary, the large pores network in the bidispersed wick creates preferential paths for the vapour and keeps a two-phase zone under the casing for a large range of heat load. This phase distribution induces a slow rise of the casing overheating.

We conclude that the mixed pore network model developed in this work is a useful tool to investigate the evaporator thermal performance and the casing temperature of an LHP/CPL for different bidispersed and monodispersed wick structures. It opens up the route towards the numerical optimisation of bidispersed capillary structures.

\section{Acknowledgements}

Financial supports from CNES and Airbus Defence and Space are gratefully acknowledged. 


\section{Appendix A. Determination of the pore distribution for the monoporous PNM}

In the pore network model, the capillary pressure is expressed as a function of throat size. The throat diameters correspond to the "pore" diameters given in the experimental data (using mercury porosimetry for example). The number of pores in the PNM is limited in order to perform the simulations for a reasonable computational time. This often results in a lower numerical porosity than the real one. The following method was adopted to obtain a porosity comparable with the real porosity of the considered sample. The method is based on the adjustment of the pore radius. The aim is to determine the appropriate pore size diameter $d_{p}$ so to have a good agreement between the given porosity and the calculated one. The wick geometrical dimension and the total numbers of pores are inputs of the model, as well as the throat radius distribution and the porosity $\varepsilon$. The process to determine $d_{p}$ is presented here for cube/cuboid representation of pores/throats, in threedimension. In the following equations the subscripts $p$ and $t$ refer to "pore" and "throat" respectively.

The porosity $\varepsilon$ of the material is given and is used as an input parameter for the model.

$\varepsilon=\frac{V_{\text {void }}}{V_{T}}$

where $V_{\text {void }}$ is the volume of void space and $V_{T}$ is the total volume of the wick. The total volume corresponds to the total volume of the wick for the considered evaporator unit cell and is simply deduced from the geometrical dimension of the wick.

The void space volume can be approximated by Eq. (A-2).

$V_{\text {void }}=V_{p} N_{p}+3 V_{t} N_{t}$

where $V_{p}$ is the volume of one pore, $V_{t}$ is the volume of one throat, $N_{p}$ is the total number of pores and $N_{t}$ is the total number of throats in the considered geometry. Note that the pore network can be viewed as the repetition in space of the pattern represented by one pore and three throats. Therefore, for a monoporous network: $N_{t}=3 N_{p}$.

Let's now express the volume of pores and throats. Pores are cubic and their volumes can be therefore expressed using Eq. (A-3).

$V_{p}=d_{p}^{3}$

Throats are considered as cuboid and their volumes are given by Eq. $(A-4)$.

$V_{t}=d_{t}^{2} l_{t}$

where $d_{t}$ is the throat diameter and $l_{t}$ the length of the throat.

The distance between two pores, i.e. nodes, is the lattice spacing, noted $a$ and is constant in each direction. Hence, the length of the throat can be expressed as the distance between two pores minus twice the pore radius.

$l_{t}=a-d_{p}$

Combining and rearranging Eqs. (A-1) from (A-5), a third degree polynomial equation is obtained with the pore diameter $d_{p}$ as unknown.

$d_{p}^{3}-\left(d_{t}^{2} \frac{N_{t}}{N_{p}}\right) d_{p}+\left(d_{t}^{2} a \frac{N_{t}}{N_{p}}-\frac{V_{T} \varepsilon}{N_{p}}\right)=0$

The classical Cardano's method is used to solve Eq. (A-6).

At this stage, the mean pore diameter $d_{p}$ is determined so as to obtain the desired porosity. However, the pore size has to be distributed randomly. Moreover, if the pore diameter is constant, this implies a constant length of throat in the network. Therefore, in order to have a random distribution of the throat's length, a standard deviation $\sigma_{r_{p}}$ of the pore size has to be determined.
As the pore diameter cannot exceed the size of a grid's mesh, i.e. $a \times a$, the standard deviation is defined by Eq. (A-7) .

$\delta_{d_{p}}=0.99 a-d_{p}$

Once pore and throat sizes are randomly distributed, the numerical porosity can be computed. This leads to a porosity very close to the desired value while keeping the disordered nature of the porous structure.

\section{Appendix B. Determination of the properties for the bidispersed PNM}

The known inputs of the model are:

- From experimental data [32]:

$\bigcirc$ the mean diameter of large pores $d_{L p, \mathbb{R}}$;

$\bigcirc$ the mean diameter of small pores $d_{s p, \mathbb{R}}$;

$\bigcirc$ the mean diameter of clusters $d_{c, \mathbb{R}}$;

$\bigcirc$ and the total porosity $\varepsilon_{\mathbb{R}}$.

- From the pore network construction:

$\bigcirc$ the volume of the wick $V_{T}$ for the considered evaporator unit cell;

$\bigcirc$ the step of the network $a$;

$\bigcirc$ and the total number of computational nodes within the wick for the considered evaporator unit cell.

The unknowns that must be specified for the construction of the pore network are:

- the porosity of the large network $\varepsilon_{L, P N}$;

- the lattice spacing of the large network $b$;

- the mean diameter of large pores $d_{L p, P N}$;

- and the mean diameter of small pores $d_{S p, P N}$.

As for the monoporous PNM, the throat diameters correspond to the pore diameters of the experimental data. Note that the clusters and pores are supposed to be circular in the real sample, while they are modelled as cubic in the pore network.

\section{B.1. Determination of large network porosity $\varepsilon_{L}$}

Each cluster is assumed to be spherical with a single contact point with its neighbours and embedded in a grid fitted on the spheres as depicted in Fig. B1. At the scale of one cluster, the cluster's volume $V_{c, \mathbb{R}}$ and the volume of one grid's cell $V_{\text {cell }}$ are:

$V_{c, \mathbb{R}}=\frac{4}{3} \pi\left(\frac{d_{c, \mathbb{R}}}{2}\right)^{3}$

$V_{\text {cell }}=d_{c, \mathbb{R}}^{3}$

Therefore, the volume of void space not occupied by the cluster in one cell is:

$V_{\text {void }, L}=V_{\text {cell }}-V_{c, \mathbb{R}}$

Note that this volume corresponds to the volume occupied by large pores. Thus, whatever, the cluster size, the theoretical porosity of the large network $\varepsilon_{L, \mathbb{t}}$ is:

$\varepsilon_{L, \mathbb{t}}=\frac{V_{\text {void }, L}}{V_{\text {cell }}}=1-\frac{\pi}{6}$

In the three-dimensional cell, the corner delimited by the red lines in Fig. B1 represents 1/8 of the total volume of one large pore. Thus, the volume of the large network void space inside one cell is equal to the volume of one large pore and is calculated as follows: $V_{L p, \mathbb{t}}=\varepsilon_{L, \mathbb{t}} V_{\text {cell }}$ 


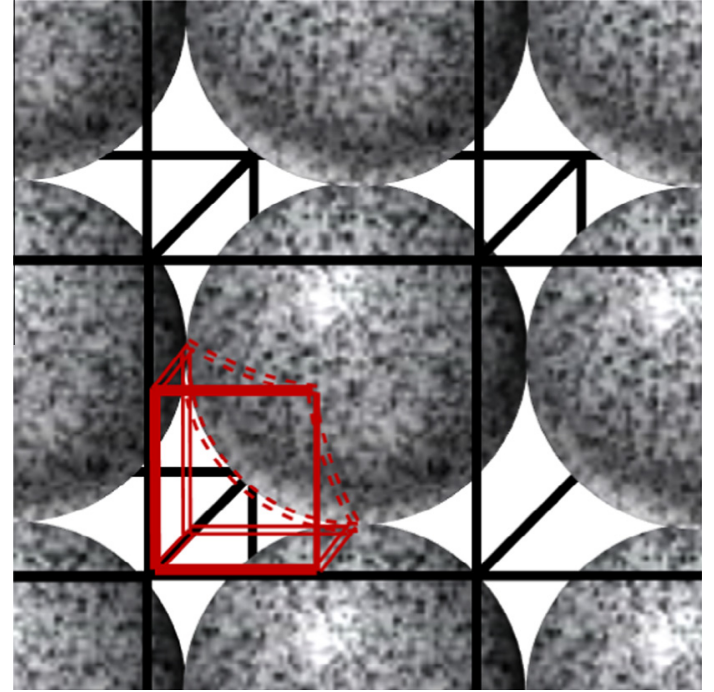

Fig. B1. Sketch of an ideal arrangement of spherical clusters (in grey), assuming a constant diameter, with a single point contact between clusters. Clusters are embedded in a grid fitted on the spheres. White space represents the location of large pores. Red lines delimited $1 / 8$ of the void space within one grid cell, i.e. $1 / 8$ of one large pore volume. (For interpretation of the references to colour in this figure legend, the reader is referred to the web version of this article.)

Considering a spherical pore, the volume of a large pore based on experimental data is:

$V_{L p, \mathbb{R}}=\frac{4}{3} \pi\left(\frac{d_{L p, \mathbb{R}}}{2}\right)^{2}$

Finally, the porosity of the large pore network is scaled as follows:

$\varepsilon_{L, \mathbb{R}}=\varepsilon_{L, \mathbb{t}} \frac{V_{L p, \mathbb{R}}}{V_{L p, \mathbb{t}}}$

Note that by deduction, the porosity of the small network is:

$\varepsilon_{S, \mathbb{R}}=\varepsilon_{\mathbb{R}}-\varepsilon_{L, \mathbb{R}}$

where $\varepsilon_{\mathbb{R}}$ is the porosity of the sample as given by the experiment.

In the PNM, the inputs for the porosities are thus:

$\varepsilon_{L, P N}=\varepsilon_{L, \mathbb{R}}$

$\varepsilon_{S, P N}=\varepsilon_{S, \mathbb{R}}$

\section{B.2. Determination of large network step $b$}

Step $b$ is determined from the comparison of the two ratios:

- Cluster number ratio: $N_{c, \mathbb{R}} / N_{c, P N}$

- Large pore number ratio: $N_{L p, \mathbb{R}} / N_{L p, P N}$

The ratios are the quantities calculated from experimental data divided by the quantities corresponding to the pore network model. Note that the number of clusters in the PNM is actually lower than in the real sample. Therefore, the number of large pores in the PNM is scaled such that:

$N_{L p, \mathbb{R}}=\frac{N_{c, P N}}{N_{c, \mathbb{R}}} N_{L p, \mathbb{R}}$

The step $b$ is then determined to satisfy condition (B-11) as close as possible. The following section described how to determine each ratio.

\section{B.2.1. Number of clusters}

From experimental data, the approximate number of clusters within the evaporator unit cell is simply defined by:

$N_{c, \mathbb{R}}=\frac{V_{T}}{V_{\text {cell }}}$

In the PNM, clusters are cubic and the volume of one cluster is:

$V_{c, P N}=b^{3}$

Therefore, the number of cluster in the PNM is defined as follows:

$N_{c, P N}=\frac{V_{T}}{V_{c, P N}}$

\section{B.2.2. Number of large pores}

From the experimental data and based on the porosity definition, the average large pore number is determined as follows:

$N_{L p, \mathbb{R}}=\varepsilon_{L, P N} \frac{V_{T}}{V_{L p, \mathbb{R}}}$

Considering that the grooves are manufactured within the casing, the following procedure is applied to determine the number of large pores within the wick. If the grooves are machined within the wick, the procedure is done twice: once for the lower part of the wick, i.e. the part close to the compensation chamber, and once for the upper part, i.e. the porous fin close to the casing; then the numbers of large pores are added. The following three values are defined:

$i=\operatorname{int}\left(\frac{n_{i}-1}{b / a}+1\right)$

$j=\operatorname{int}\left(\frac{n_{j w}-1}{b / a}+1\right)$

$k=\operatorname{int}\left(\frac{n_{k}-1}{b / a}+1\right)$

where $n_{i}$ is the number of pore in the $x$ direction, $n_{j w}$ is the number of pores in the $y$ direction, $n_{k}$ is the number of pores in the $z$ direction; int is a function which returns the integer part of the number obtained inside brackets. Actually, $i$ returns the number of planes $(y O z)$ defining the junction between two clusters in the $x$ direction, $j$ returns the number of planes $(x O z)$ defining the junction between two clusters in the $y$ direction and $k$ returns the number of planes $(x O y)$ defining the junction between two clusters in the $z$ direction.

Finally, the total number of large pores in the network is:

$N_{L p, P N}=n_{i} \times j \times k+\left(n_{j w}-j\right) \times i \times k+\left(n_{k}-k\right) \times i \times j$

Note that the total number of large throats in the network is:

$N_{L t, P N}=N_{L p, P N}+2 \times i \times j \times k$.

\section{B.2.3. Ratio comparison}

Combining Eqs. (B-12)-(B-19), the step $b$ is determined such that the number of clusters ratio $N_{c, \mathbb{R}} / N_{c, P N}$ and the number of large pores ratio $N_{L p, \mathbb{R}} / N_{L p, P N}$ are as close as possible.

\section{B.3. Determination of the pore size $d_{L p, P N}$ and $d_{S p, P N}$}

Finally, the mean diameter of pores and throats are determined following the procedure given in Appendix A. The two third degree polynomial equations to solve for the large network and the small network respectively are given by Eqs. (B-21) and (B-22) respectively. 


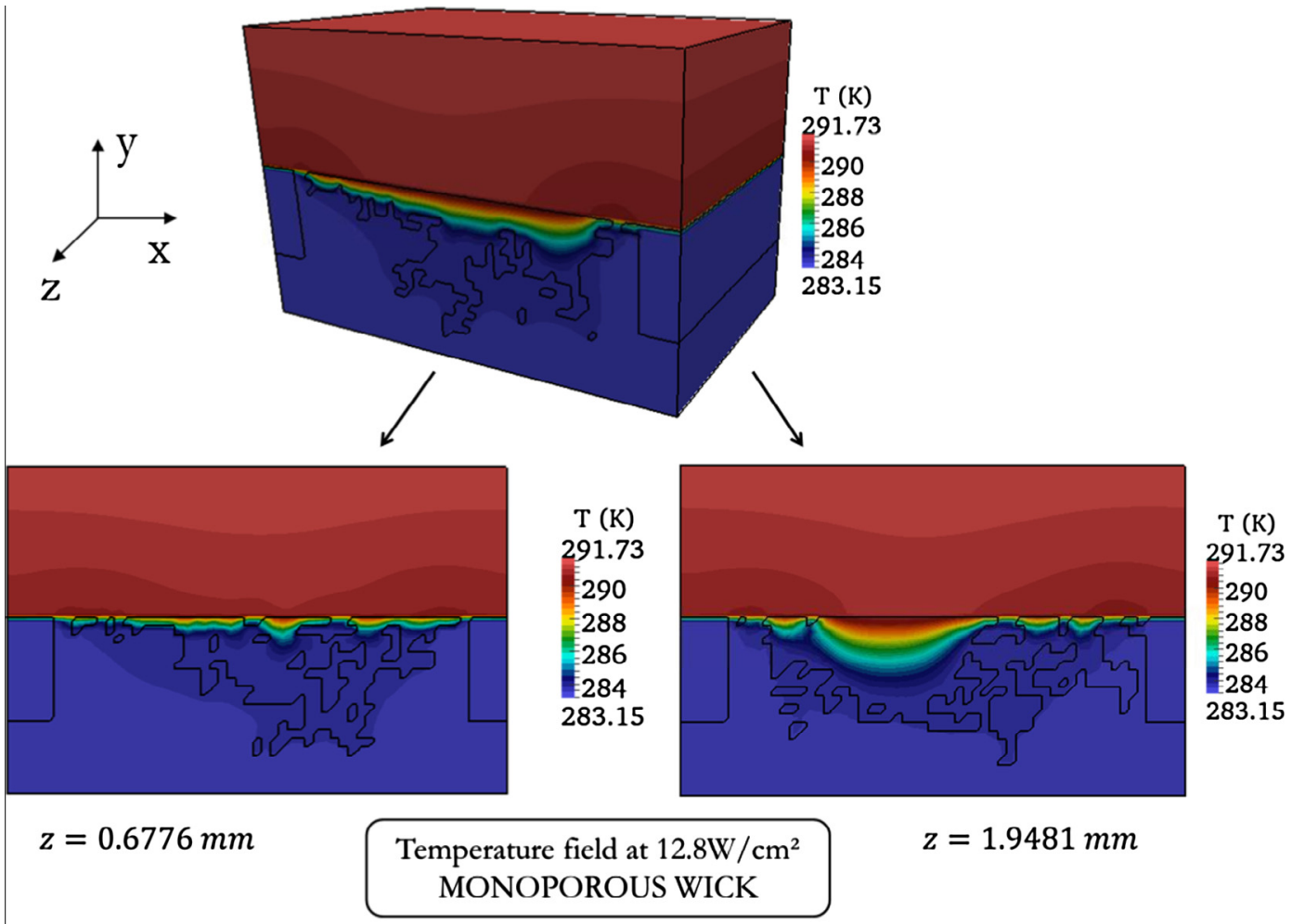

(a)

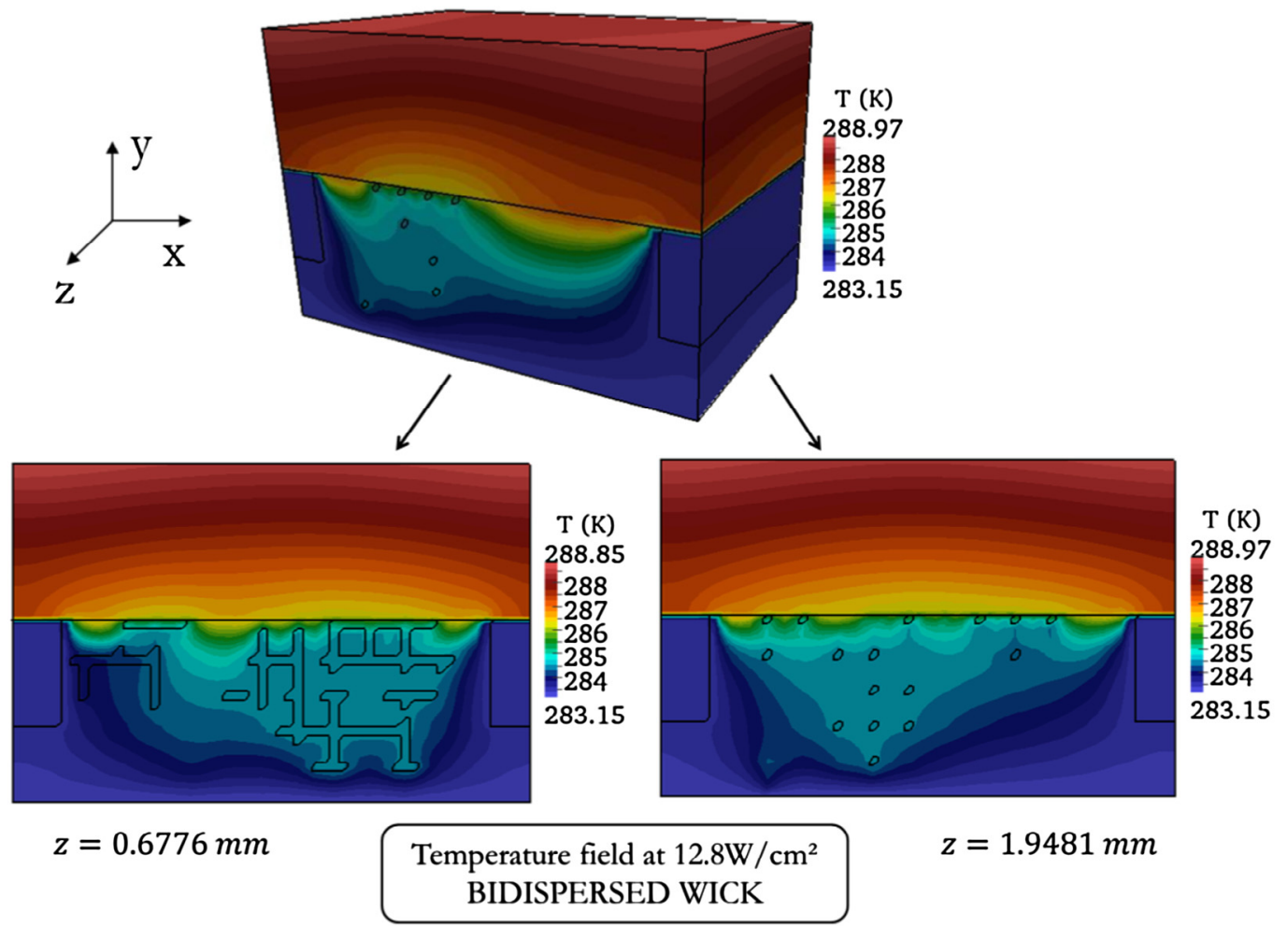

(b)

Fig. C1. Temperature fields within the capillary evaporator unit cell for heat load equal to $12.8 \mathrm{~W} / \mathrm{cm}^{2}$ for (a) the monoporous wick and (b) the bidispersed wick. Black lines delimit the shape of the vapour phase within the wick. 


$$
\begin{aligned}
& d_{L p, P N}^{3}-\left(d_{L t, P N}^{2} \frac{N_{L t, P N}}{N_{L p, P N}}\right) d_{L p, P N}+\left(d_{L t, P N}^{2} a \frac{N_{L t, P N}}{N_{L p, P N}}-\frac{V_{T} \varepsilon_{L, P N}}{N_{L p, P N}}\right)=0 \\
& d_{S p, P N}^{3}-\left(d_{S t, P N}^{2} \frac{N_{S t, P N}}{N_{S p, P N}}\right) d_{S p, P N}+\left(d_{S t, P N}^{2} a \frac{N_{S t, P N}}{N_{S p, P N}}-\frac{V_{T} \varepsilon_{S, P N}}{N_{S p, P N}}\right)=0
\end{aligned}
$$

\section{Appendix $C$. Temperature fields for the monoporous and the bidispersed wick}

As an example, temperature fields for heat load equal to $12.8 \mathrm{~W} / \mathrm{cm}^{2}$ are given for the monoporous and the bidispersed wick. As said in Section 5.3, the compensation chamber (CC) temperature is an input in our model and was fixed at $283.15 \mathrm{~K}$. With this temperature for the $\mathrm{CC}$, the maximal temperature of the evaporator, located at the casing external surface, obtained numerically, was lower than the one obtained experimentally.

\section{References}

[1] Y.F. Maydanik, Loop heat pipes, Appl. Therm. Eng. 25 (2005) 635-657, http:// dx.doi.org/10.1016/j.applthermaleng.2004.07.010.

[2] S. Launay, V. Sartre, J. Bonjour, Parametric analysis of loop heat pipe operation: a literature review, Int. J. Therm. Sci. 46 (2007) 621-636, http://dx.doi.org/ 10.1016/j.ijthermalsci.2006.11.007.

[3] T. Kaya, R. Pérez, C. Gregori, A. Torres, Numerical simulation of transient operation of loop heat pipes, Appl. Therm. Eng. 28 (2008) 967-974, http://dx. doi.org/10.1016/j.applthermaleng.2007.06.037.

[4] B. Siedel, V. Sartre, F. Lefèvre, Numerical investigation of the thermohydraulic behaviour of a complete loop heat pipe, Appl. Therm. Eng. 61 (2013) 541-553, http://dx.doi.org/10.1016/j.applthermaleng.2013.08.017.

[5] M.A. Chernysheva, Y.F. Maydanik, Numerical simulation of transient heat and mass transfer in a cylindrical evaporator of a loop heat pipe, Int. J. Heat Mass Transf. 51 (2008) 4204-4215, http://dx.doi.org/10.1016/j.ijheatmasstransfer. 2007.12.021.

[6] M.A. Chernysheva, Y.F. Maydanik, Simulation of thermal processes in a flat evaporator of a copper-water loop heat pipe under uniform and concentrated heating, Int. J. Heat Mass Transf. 55 (2012) 7385-7397.

[7] L. Mottet, T. Coquard, M. Prat, Three dimensional liquid and vapour distribution in the wick of capillary evaporators, Int. J. Heat Mass Transf. 83 (2015) 636-651, http://dx.doi.org/10.1016/j.ijheatmasstransfer.2014.12.048.

[8] Y. Cao, A. Faghri, Analytical solutions of flow and heat transfer in a porous structure with partial heating and evaporation on the upper surface, Int. J. Heat Mass Transf. 37 (1994) 1525-1533.

[9] J. Li, G.P. Peterson, 3D heat transfer analysis in a loop heat pipe evaporator with a fully saturated wick, Int. J. Heat Mass Transf. 54 (2011) 564-574, http://dx. doi.org/10.1016/j.ijheatmasstransfer.2010.09.014.

[10] X. Zhang, X. Li, S. Wang, Three-dimensional simulation on heat transfer in the flat evaporator of miniature loop heat pipe, Int. J. Therm. Sci. 54 (2012) 188-198, http://dx.doi.org/10.1016/j.ijthermalsci.2011.12.002.

[11] A.S. Demidov, E.S. Yatsenko, Investigation of heat and mass transfer in the evaporation zone of a heat pipe operating by the "inverted meniscus " principle, Int. J. Heat Mass Transf. 37 (1994) 2155-2163.

[12] C. Figus, Y. Le Bray, S. Bories, M. Prat, Heat and mass transfer with phase change in a porous structure partially heated: continuum model and pore network simulations, Int. J. Heat Mass Transf. 42 (1999) 2557-2569.

[13] T. Kaya, J. Goldak, Numerical analysis of heat and mass transfer in the capillary structure of a loop heat pipe, Int. J. Heat Mass Transf. 49 (2006) 3211-3220, http://dx.doi.org/10.1016/j.ijheatmasstransfer.2006.01.028.

[14] T. Zhao, Q. Liao, On capillary-driven flow and phase-change heat transfer in a porous structure heated by a finned surface: measurements and modeling, Int. J. Heat Mass Transf. 43 (2000) 1141-1155.

[15] Y.H. Yan, J.M. Ochterbeck, Numerical investigation of the steady-state operation of a cylindrical capillary pumped loop evaporator, J. Electron. Packag. 125 (2003) 251, http://dx.doi.org/10.1115/1.1569509.

[16] X. Huang, W. Liu, A. Nakayama, S.W. Peng, Modeling for heat and mass transfer with phase change in porous wick of CPL evaporator, Heat Mass Transf. 41 (2005) 667-673, http://dx.doi.org/10.1007/s00231-004-0609-2.

[17] M.A. Chernysheva, Y.F. Maydanik, Heat and mass transfer in evaporator of loop heat pipe, J. Thermophys. Heat Transf. 23 (2009) 725-731, http://dx.doi.org/ $10.2514 / 1.43244$

[18] Y. Cao, A. Faghri, Conjugate analysis of a flat-plate type evaporator for capillary pumped loops with three-dimensional vapor flow in the groove, Int. J. Heat Mass Transf. 37 (1994) 401-409.
[19] Y. Xuan, K. Zhao, Q. Li, Investigation on heat and mass transfer in a evaporator of a capillary-pumped loop with the lattice boltzmann method: pore scale simulation, Transp. Porous Media 89 (2011) 337-355, http://dx.doi.org/ 10.1007/s11242-011-9774-1.

[20] T. Coquard, Transferts couplés de masse et de chaleur dans un élément d'évaporateur capillaire, 2006.

[21] R. Singh, A. Akbarzadeh, M. Mochizuki, Effect of wick characteristics on the thermal performance of the miniature loop heat pipe, J. Heat Transfer 131 (2009) 082601, http://dx.doi.org/10.1115/1.3109994.

[22] S.-C. Wu, C.-J. Huang, S.-H. Chen, Y.-M. Chen, Manufacturing and testing of the double-layer wick structure in a loop heat pipe, Int. J. Heat Mass Transf. 56 (2013) 709-714, http://dx.doi.org/10.1016/j.ijheatmasstransfer.2012.09.054.

[23] N.S. Rasor, J.L. Desplat, K-max: a material with exceptional heat transfer properties, 1989.

[24] C.-C. Yeh, C.-N. Chen, Y.-M. Chen, Heat transfer analysis of a loop heat pipe with biporous wicks, Int. J. Heat Mass Transf. 52 (2009) 4426-4434, http://dx. doi.org/10.1016/j.ijheatmasstransfer.2009.03.059.

[25] M.T. North, D.B. Sarraf, J.H. Rosenfeld, Y.F. Maydanik, S.V.V Vershinin, High heat flux loop heat pipes, in: 6th European Symposium on Space Environmental Control Systems, Noordwijk, The Netherlands, 1997.

[26] X.L. Cao, P. Cheng, T.S. Zhao, Experimental study of evaporative heat transfer in sintered copper bidispersed wick structures, J. Thermophys. Heat Transfer 16 (2002) 547-552.

[27] T. Semenic, Y.Y. Lin, I. Catton, Use of liquid film evaporation in biporous media to achieve high heat flux over large areas, in: ASME Summer Heat Transfer Conference, 2005, pp. 1-6.

[28] T. Semenic, Y.Y. Lin, I. Catton, Use of liquid film evaporation in biporous media to achieve high heat flux over large areas, in: VI Minsk International Seminar "Heat Pipes, Heat Pumps, Refrigerators", 2005, pp. 45-51.

[29] T. Semenic, Y.Y. Lin, I. Catton, Thermophysical properties of biporous heat pipe evaporators, J. Heat Transfer 130 (2008) 022602, http://dx.doi.org/10.1115/ 1.2790020.

[30] T. Semenic, Y.Y. Lin, I. Catton, D.B. Sarraf, Use of biporous wicks to remove high heat fluxes, Appl. Therm. Eng. 28 (2008) 278-283, http://dx.doi.org/10.1016/j. applthermaleng.2006.02.030.

[31] T. Semenic, I. Catton, Experimental study of biporous wicks for high heat flux applications, Int. J. Heat Mass Transf. 52 (2009) 5113-5121, http://dx.doi.org/ 10.1016/j.ijheatmasstransfer.2009.05.005.

[32] F.-C. Lin, B.-H. Liu, C.-C. Juan, Y.-M. Chen, Effect of pore size distribution in bidisperse wick on heat transfer in a loop heat pipe, Heat Mass Transf. 47 (2011) 933-940, http://dx.doi.org/10.1007/s00231-011-0841-5.

[33] C.-C. Yeh, B.-H. Liu, Y.-M. Chen, A study of loop heat pipe with biporous wicks, Heat Mass Transf. 44 (2008) 1537-1547, http://dx.doi.org/10.1007/s00231008-0387-3.

[34] S.-C. Wu, D. Wang, W.-J. Lin, Y.-M. Chen, Investigating the effect of powdermixing parameter in biporous wick manufacturing on enhancement of loop heat pipe performance, Int. J. Heat Mass Transf. 89 (2015) 460-467, http://dx. doi.org/10.1016/j.ijheatmasstransfer.2015.05.074.

[35] S.-C. Wu, B.H. Hsieh, D. Wang, Y.-M. Chen, Manufacture of a biporous nickel wick and its effect on LHP heat transfer performance enhancement, Heat Mass Transf. (2015), http://dx.doi.org/10.1007/s00231-015-1503-9.

[36] H. Li, Z. Liu, B. Chen, W. Liu, C. Li, J. Yang, Development of biporous wicks for flat-plate loop heat pipe, Exp. Thermal Fluid Sci. 37 (2012) 91-97, http://dx. doi.org/10.1016/j.expthermflusci.2011.10.007.

[37] S.-C. Wu, F.-C. Lin, S.-H. Chen, C.-C. Yeh, S.K. Wang, Y.-M. Chen, Manufacturing of the complex wick with double-layer bi-porous structure and applying to a loop heat, in: 10th International Heat Pipe Symposium, 2011, pp. 104-108.

[38] J. Wang, I. Catton, Evaporation heat transfer in thin biporous media, Heat Mass Transf. 37 (2001) 275-281.

[39] A. Vadnjal, I. Catton, Modelling heat transfer performance of a thin bi-porous evaporator for a heat pipe, in: ASME Summer Heat Transfer Conference, 2005.

[40] S.W. Reilly, I. Catton, Utilization of pore-size distributions to predict thermophysical properties and performance of biporous wick evaporators, J. Heat Transfer 136 (2014) 061501, http://dx.doi.org/10.1115/1.4026624.

[41] M.A. Chernysheva, Y.F. Maydanik, Heat and mass investigation in the evaporation zone of a loop heat pipe, in: 7th Minsk International Conference "Heat Pipes, Heat Pumps, Refrigerators, Power Sources", 2008, pp. 79-86.

[42] F.-C. Lin, B.-H. Liu, C.-T. Huang, Y.-M. Chen, Evaporative heat transfer model of a loop heat pipe with bidisperse wick structure, Int. J. Heat Mass Transf. 54 (2011) 4621-4629, http://dx.doi.org/10.1016/j.ijheatmasstransfer.2011.06. 015.

[43] C. Sleicher, M. Rouse, A convenient correlation for heat transfer to constant and variable property fluids in turbulent pipe flow, Int. J. Heat Mass Transf. 18 (1975) 677-683.

[44] S. Patankar, Numerical heat transfer and fluid flow, 1980

[45] S.-C. Wu, T.-W. Gu, D. Wang, Y.-M. Chen, Study of PTFE wick structure applied to loop heat pipe, Appl. Therm. Eng. 81 (2015) 51-57, http://dx.doi.org/ 10.1016/j.applthermaleng.2015.01.048. 